\title{
CLIMATE SYSTEM RESEARCH
}

\author{
SECOND ANNUAL REPORT \\ for the Period December 1, 1989 - November 30, 1990
}

\author{
R.S. Bradley \\ University of Massachusetts, Amherst
}

\begin{abstract}
H.F. Diaz
NOAA, Enivronuiserital Research Laboratories
\end{abstract}

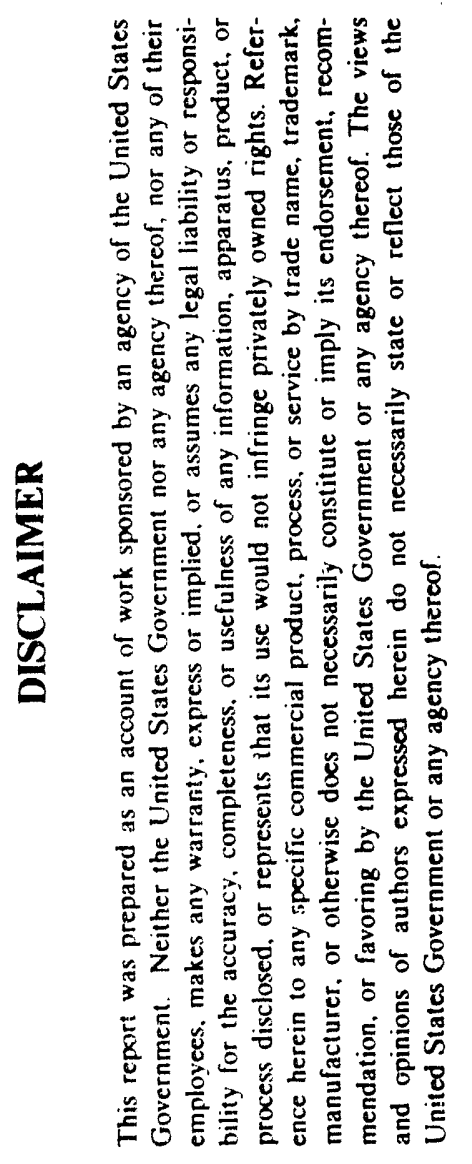

\author{
P.D. Jones and P.M Kelly \\ Climatic Research Unit \\ University of East Anglia, Norwich, U.K.
}

September 1990

Prepared for

THE U.S. DEPARTMENT OF ENERGY

AGREEMENT NO. DE-FGO2-89ER69017

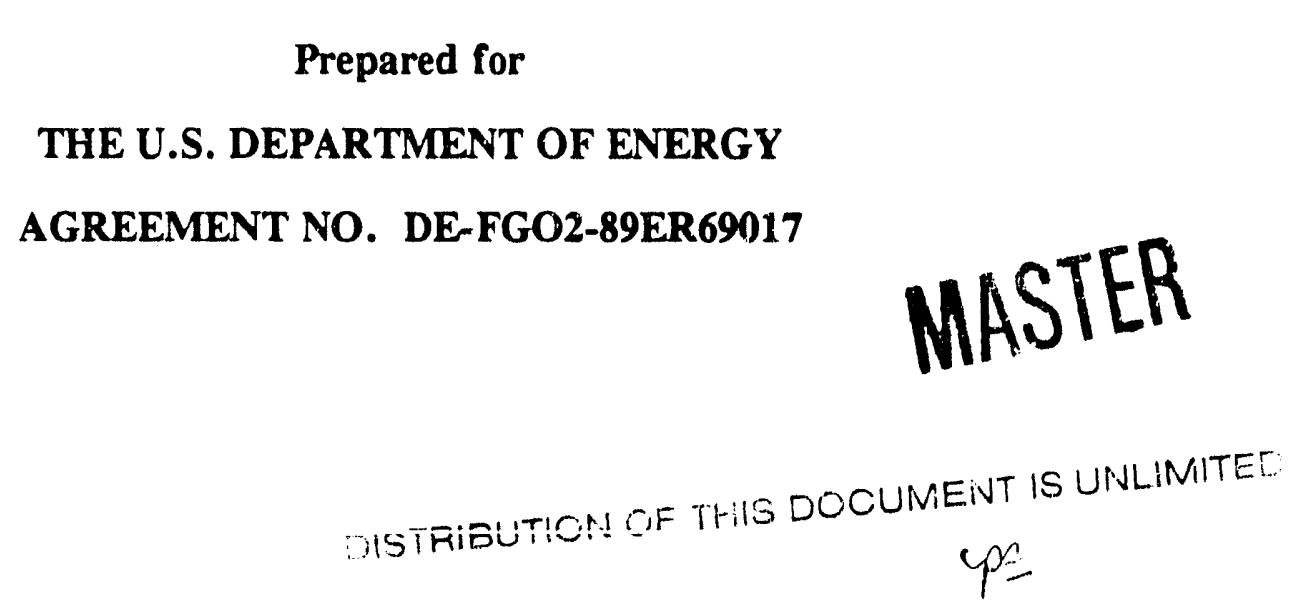

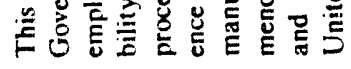




\section{A. Precipitation Data}

A major effort in Year 2 of the grant period was up-dating and expansion of the precipitation data set, previously used in analyses by Bradley et al.(1987) and Diaz et al (1989). This effort has involved work in parallel by NOAA and the University of Massachusetts, in the U.S., and by the University of East Anglia, in the U.K., using the particular international contacts and networks available to each group. The results have significantly improved data coverage in time and space. However, merging of our individual efforts remains to be carried out to identify duplications where apparent, and to define the "Department of Energy precipitation data set, Version 1.0" that can be made available fo: general public distribution. A first step towards this goal is described (in draft form) in Appendix 1. Here, effort was focused on the analaysis of regional and large scale precipitation changes shown by the observational record (Diaz and Eischeid, 1990). A reassessment of precipitation changes over global land areas, using the new expanded data set and different approaches to expressing precipitation change, confirms earlier results (op. cit.). Precipitation over the continents decreased from the late 19th to the early 20 th century by 4 $5 \%$; an increase of $-5 \%$ occurred around $1945-55$, leading to highest precipitation amounts in the mid-1970s (Figure 1). Since then, precipitation over the continents has declined by $3-4 \%$ (Eischeid et al., 1990). These results appear to confirm the view expressed in Bradley and Groisman (1990) that the observed large-scale changes are robust to changes in methodology and database employed.

In addition to these studies of long-term precipitation change, a grid-based precipitation data set for use in model validation studies has been prepared. For this purpose, a denser network of stations covering a shor er period can be employed. The period 1951-80 was selected as it contains the greatest station density over land areas of the world. For a station to be included in this climatology, it must have at least $90 \%$ of all monthly values for the reference period; 2553 stations meet this requirement. As well as long-term statistics for the reference period, monthly data are being made availabie for studies of variability. 


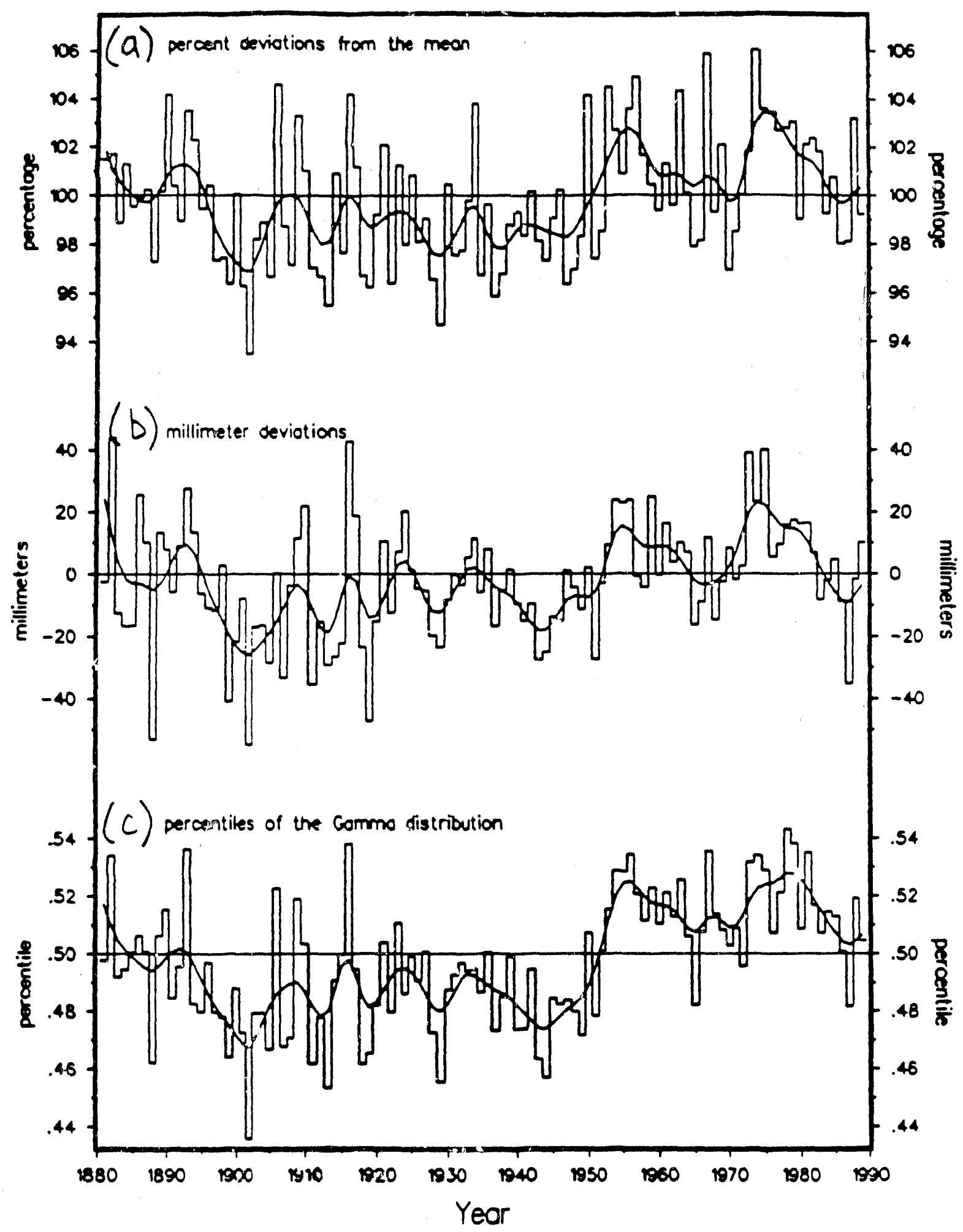

Figure 1: Variations in annual continental precipitation (both hemispheres):
A) \% deviations from the 1951-70 mean
B) departures from 1951-70 mean in millimeters
C) perenntiles of the gamma distribution 
Precipitation estimates have, been produced at $5^{\circ}$ resolution from the station records, thus the gridboxes vary from $308,600 \mathrm{~km}^{2}$ at the equator to $13,300 \mathrm{~km}^{2}$ near the poles. For zonal, hemispheric and global precipitation estimates, these individual gridboxes are weighted by area.

To ensure compatibility with model estimates of precipitation, which are in the form of average precipitation depth over a gridbox rather than a point estimate, it was necessary to generate area average precipitation data from the individual station records. These areal estimates were produced using a Thiessen polygon approach. The area under consideration was divided into $n$ zones of influence $S_{i}$, one for each station. The zone of influence of a station is defined by the area which is closer to that gauge than to any other. Station weights were then derived as:

$$
\alpha_{\mathrm{i}}=\mathrm{S}_{\mathrm{i}} / \mathrm{S} \quad \mathrm{i}=1 \ldots, \mathrm{n}
$$

where $S_{i}$ is the area of influence of station $i$ and $S$ is the total area of the gridbox (i.e. the sum of all the $\mathrm{S}_{\mathrm{i}}$ ). This weighting systems avoids bias caused by clustering of stations within a gridbox.

A criteria of $<10 \%$ missing values was used to select contributing station series. Of the resulting 2553 series, only 500 were fully complete, and the total aumber of missing months in the 1951-80 reference period was 3456 , i.e. $3.4 \%$. The percentage ranged from 0 to $7.6 \%$ for any given year. The small number of missing values in the reference period was estimated using the following procedure. A mean gridbox percentage anomaly for the gridbox-month which contained the missing value was calculated at station $\mathrm{m}$ from the remaining stations using the 1951-80 station means. The missing monthly value for station $\mathrm{m}$ was than estimated by converting the mean gridbox-month percentage anomaly into a mm value using the 1951-80 monthly mean of the valid data in the gridbox. The number of gridboxes where there are one or more station-months with no resulting precipitation estimate was 234 , i.e. $0.5 \%$. 
The result of this analysis is a data set of monthly precipitation of the period 1951-80 in $\mathrm{mm}$ units on a $5^{\circ}$ grid. Area average precipitation estimates are, therefore, available for 597 gridboxes, representing $28 \%$ of the surface area of the earth. These gridboxes are largely continental in location, although parts of the central and western Pacific ocean are covered as well as isolated gridboxes within the Indian and Atlantic Oceans. Figure $2 \mathrm{a}$ shows the frequency distribution of stations per gridbox, and Figure $2 b$ the spatial distribution of these frequencies. The gridboxes with the largest number of contributing stations (over 20) are concentrated over the western USA, western Europe, northeast Brazil, southeast Australia and parts of southern Africa.

Changes of precipitation in Arctic regions with incresing greenhouse gas concentrations are of particular significance in view of the importance of snowfall to regional and global albedo and to sea-level changes. Equilibrium model-generated changes in high latitude snowfall amounts have been examined for several different model runs (GISS, OSU, GFDL and NCAR). Very large differences are recorded between these models and little regional cohernce is apparent. Since Arctic precipitation is strongly related to temperature, empirical relationships between precipitation and temperature were examined and compared with modelgenerated temperature changes for $2 \mathrm{X} . \mathrm{CO}_{2}$ conditions. Results suggest that model estimates of precipitation changes are larger than can be expected with the accompanying temperature changes predicted by the models (Figures $3 a$ and $3 b$ ). Further work on this matter is in progress.

\section{B. Temperature data.}

A number of authors have presented circumstantial evidence that solar variability may be a significant contributor to the long-term warming trend observed in the global-mean surface air temperature record since the mid-19th century. We have considered the role of irradiance changes associated with the solar (sunspot) cycle, extending an analysis by Reid (1987). Reid used an upwelling-diffusion, energy balance climate model to determine the best 
Station frequency per 5 deg gridbox

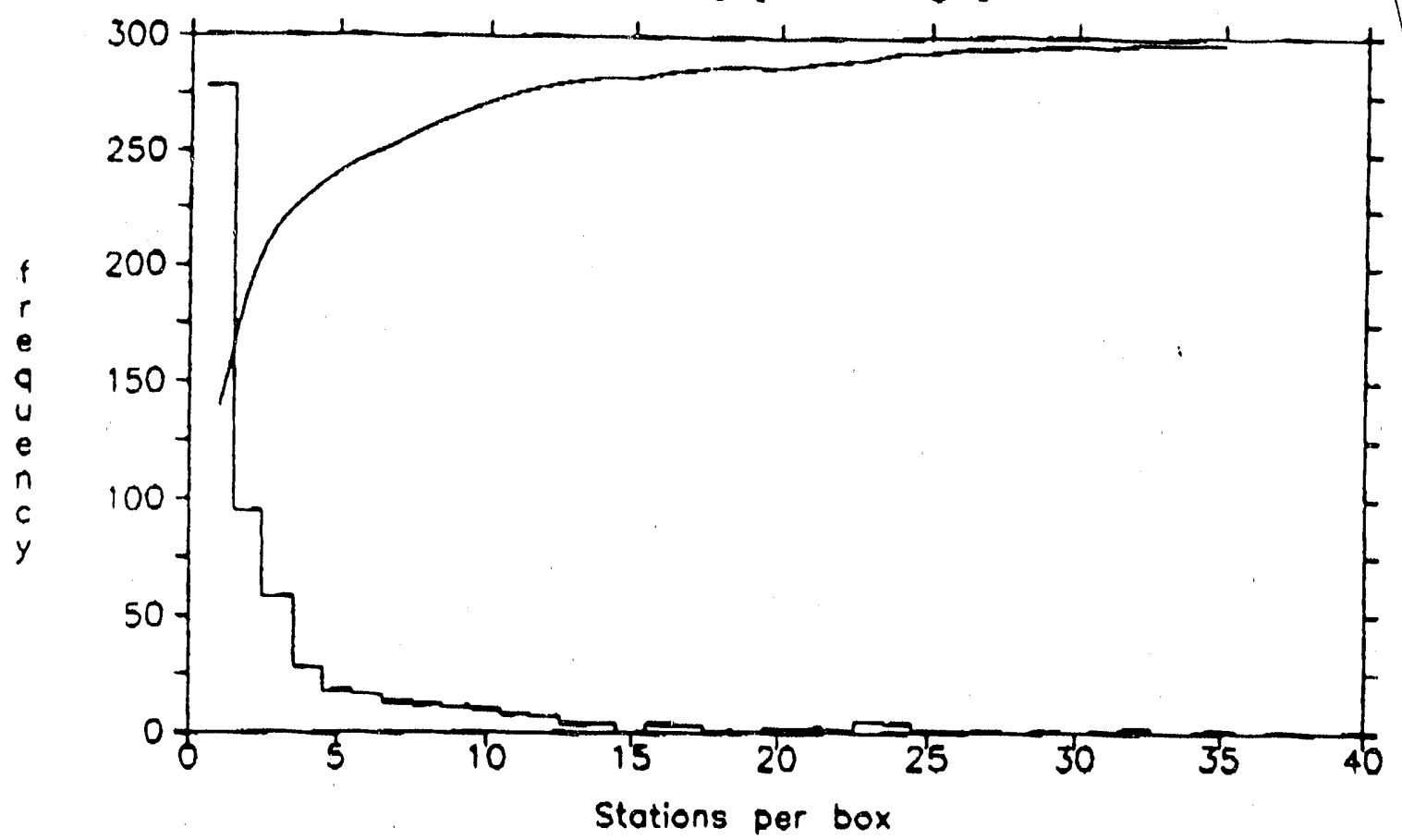

Figure $2 a$

Station frequency per 5 degree gridbox.

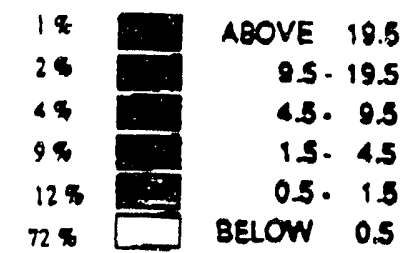

Gridbox coverage using 1951-80 reference

Nuraber of $S$ deg boxes filled $=597$

Number of itatioas $=2546$

18. Narno (\% of globe covered $=28$ )

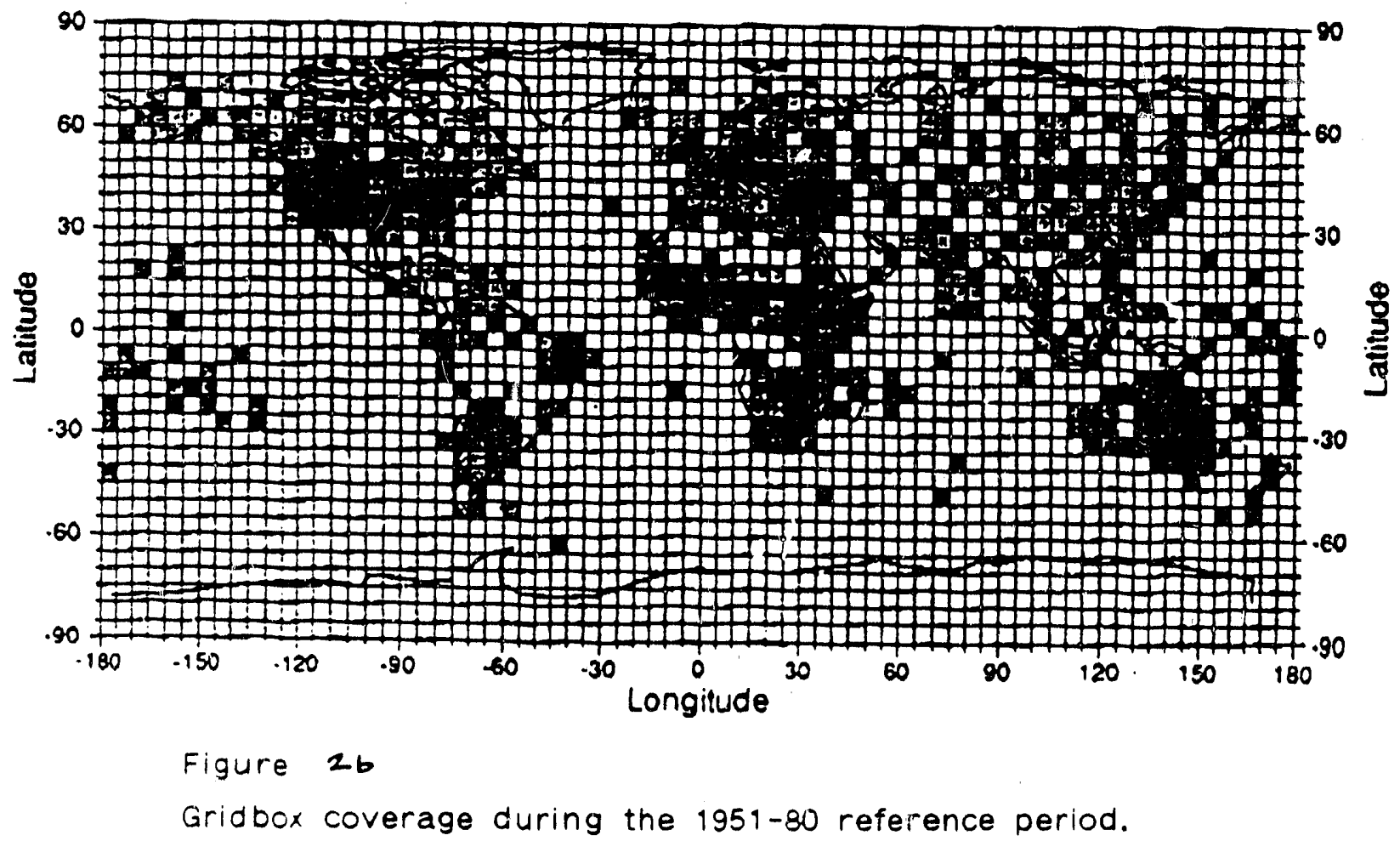




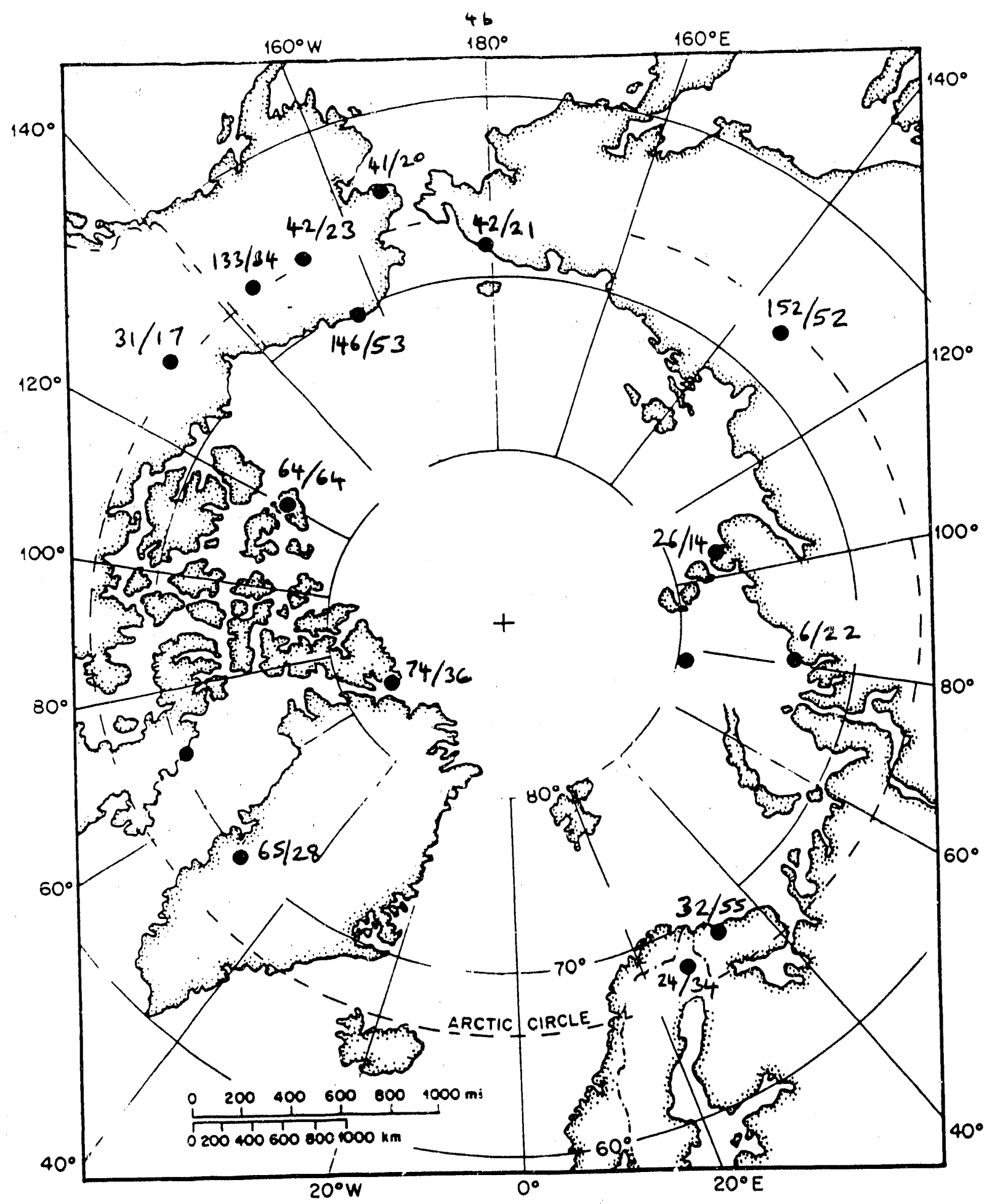

Figure 3a. Prosted percentage increases in annual precipitation with a doubling of $\mathrm{CO}_{2}$. NCAR CCM/OSU GCM. 


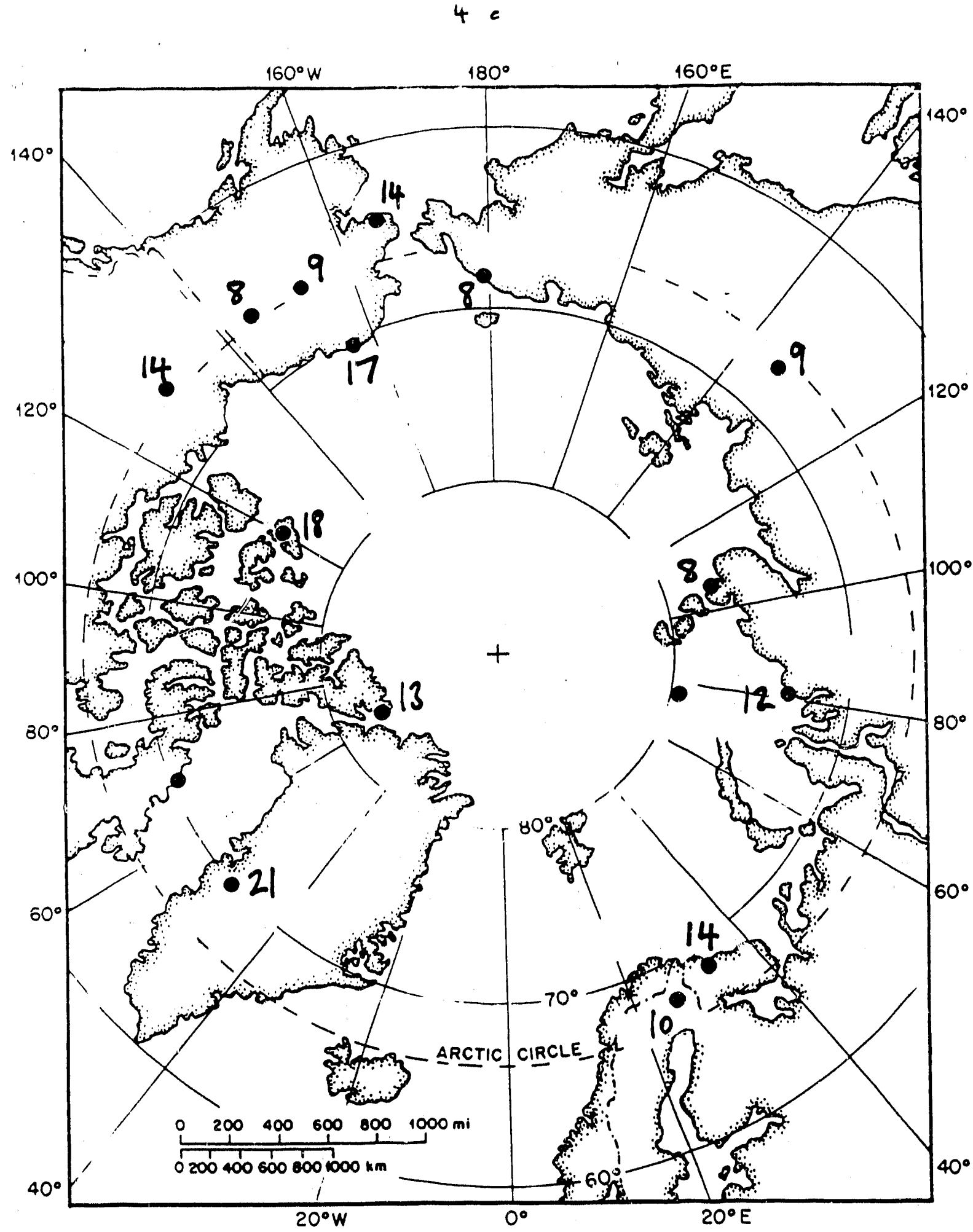

Figure 3b. Estimates of percent change in annual precipitation for the temperature change predicted bt NCAR CCM with $2 \mathrm{X} \mathrm{CO}_{2}$, using empirical relationship between temperature and precipitation. 
fit between the record of sunspot numbers, taken as a proxy for variations in solar irradiance, and the global-mean sea surface temperature record derived by Folland $e t$ al. (1984), both with and without additional forcing due to enhancement of the greenhouse effect.

Reid assumed a simple relationship between sunspot number and long-term variations in the solar constant, $\mathrm{S}$ :

$$
S_{t}=S_{0}\left[1+\alpha\left(N_{t}-N_{0}\right)\right]
$$

where $N_{1}$ is the sunspot number at time $t$ after application of an 11-year running mean and $S_{0}$ and $\mathrm{N}_{0}$ are reference values. The constant $\alpha$ was varied to identify a subjective best fit between the amplitude of the modelled and observed temperature changes. Reid only presented results for one value of the climate sensitivity, corresponding to a $2.5^{\circ} \mathrm{C}$ equilibrium global-mean temperature rise for a doubling of atmospheric carbon dioxide concentrations. We have extended his analysis by considering a range of climate sensitivities and by identifying the best fit in a quantitative fashion.

In order to assess how global-mean temperature should respond to forcing variations, use was made of a model of the climate system developed by Wigley and Raper (1987) which is conceptually the same as the model used by Reid. Two basic experiments were undertaken. First, it was assumed that solar variability alone is responsible for the observed fluctuations in global-mean temperature. Following Reid, changes in solar radiative forcing, $\delta Q$, are assumed to be related to changes in sunspot number, $\delta \mathrm{N}$, by $\delta \mathrm{Q}=\beta \delta \mathrm{N}$, and the best-fit value of $B$, the solar forcing scaling factor, was identified for a range of climate sensitivity values. Since there is no doubt that the marked rise in greenhouse-gas concentrations over the past $f \in W$ centuries has had a direct radiative forcing effect, it is, in fact, illogical to consider solar effects in isolation. We considered this first possibility only for the sake of completeness. Our second experiment more realistically combined forcing due to enhancement of the greenhouse effect and a solar contribution which varied with $B$.

In both experiments, the solar forcing scaling factor, $B$, was allowed to vary between 0.02 and 0.04 in increments of 0.002 . Recent satellite observations suggest that the value of $B$ 
is about +0.001 [see, for example, Foukal and Lean (1990)]. This value results in a negligible solar effect on global-mean temperature [cf. Wigley and Raper (in press)]. It should be noted, though, that this estimate of $B$ is derived from observations taken during a limited period of the 11-year sunspot sycle and may not be representative of longer-term relationships. There is some evidence of a link between global climate change and solar variability on century and longer timescales which would imply a greater value of $B$ at lower frequencies [see, for example, Wigley and Kelly (1990)]. Although rather speculative, the possibility cannot be ruled out.

The climate sensitivity was specified in terms of the equilibrium global-mean temperature change for a carbon dioxide doubling, $\delta \mathrm{T}_{2 \mathrm{x}}$. This was varied between 1.0 and $5.0^{\circ} \mathrm{C}$ in increments of $0.5^{\circ} \mathrm{C}$, spanning the current range of uncertainty. For greenhouse forcing, concentration histories and concentration/forcing relationships for the major greenhouse gases (carbon dioxide, chlorofluorocarbons, methane and nitrous oxide) recommended by Working Group 1 of the Intergovernmental Panel on Climate Change were used. The simulations extend from 1765 to 1989.

The best fit between modelled and observed temperature was determined, for the values of $B$ and $\delta T_{2 x}$ specified earlier, by the root mean square error, $\mathrm{E}_{\mathrm{rms}}$ :

$$
\mathrm{E}_{\mathrm{rms}}=\sqrt{1 / \mathrm{N}} \cdot \Sigma\left(\mathrm{O}_{\mathrm{l}}-\mathrm{M}_{\mathrm{l}}\right)^{2}
$$

where $\mathrm{O}_{\mathrm{t}}$ and $\mathrm{M}_{\mathrm{t}}$ are departures in the observed and modelled yearly temperatures from their respective 1861-1989 means and $\mathrm{N}$ is the number of annual observations $(\mathrm{N}=139)$.

As an indicator of global-mean temperature, Reid used the sea surface temperature record, as his earlier work had indicated an apparent correlation between sunspot numbers and tropopause height over the western tropical Pacific. There is, however, no reason to expect that there should be any difference between the response of land and ocean temperature to variations in solar irradiance on decadal and longer timescales. Here, we base our analysis on the latest estimate of global-mean surface air temperature derived from both land and marine observations, as described in the Report of Working Group 1 of the Intergovernmental Panel 
on Climate Change (Figure 4). The results presented in this paper are based on analysis of the complete record, extending from 1861 to 1989.

To test reproducibility, we repeated the analysis on the more reliable subset of this record, which covers the period 1905-89, and on the global-mean sea surface temperature record used by Reid; there were no significant differences between the results. We have also used both a low-pass filtered sunspot record (following Reid, who used an 11-year running mean to define long-term variations in th.s record) and the unfiltered record. The following discussion is based on analysis of the filtered data to ensure compatibility with Reid; reference is made to any substantial differences in the results based on the unfiltered data.

Figure 5 shows the variation of the root mean square error, $\mathrm{E}_{\mathrm{rms}}$, with $\beta$ and $\delta \mathrm{T}_{2 \mathrm{x}}$ when solar forcing alone is specified. For a carbon dioxide doubling temperature rise of $2.5^{\circ} \mathrm{C}, \mathrm{E}_{\mathrm{rms}}$ reaches a minimum at $\beta=0.019$. This is in troad agreement with Reid's findings (for his best-fit value of $\alpha, 1.08 * 10^{-4}, \beta=0.025$ ). However, somewhat better fits (i.e., lower $\mathrm{E}_{\mathrm{Tms}}$ ) can be obtained for larger values of $\delta \mathrm{T}_{2 \mathrm{x}}$, requiring progressively smaller values of $\beta$. Within the range of $\delta \mathrm{T}_{2 \mathrm{x}}$ values considered, the lowest $\mathrm{E}_{\mathrm{Tms}}$ is reached when $\delta \mathrm{T}_{2 \mathrm{x}}=5.0^{\circ} \mathrm{C}$ and $\beta=0.012$. Although this could be judged to be an optimum solution, it is difficult to justify for two reasons. First, this value of $\beta$ is more than ten times that suggested by recent satellite observations. Second, such a high climate sensitivity would have to have produced a large greenhouse warming. Sub-optimal solutions for lower $\delta \mathrm{T}_{2 \mathrm{x}}$ are close to this optimal solution, but these, ton, are unlikely because, as $\delta \mathrm{T}_{2 \mathrm{x}}$ decreases, the implied $B$ value rises, becoming increasingly implausible in the light of the value suggested by the satellite data. When unfiltered, rather than filtered, sunspot data are used, $\mathrm{E}_{\mathrm{rms}}$ increases considerably when $\delta \mathrm{T}_{2 \mathrm{x}}$ is towards the lower end of the range.

We now consider the more plausible hypothesis that the observed trend in global-mean temperature is explained by a combination of greenhouse and solar forcing. Figure ? shows the variation of $E_{T m s}$ with $B$ and $\delta T_{2 x}$ in this sase. With zero solar forcing (i.e., $\beta=0.0$ ), $\mathrm{E}_{\mathrm{rms}}$ is at a minimum when $\delta \mathrm{T}_{2 \mathrm{x}}=1.5^{\circ} \mathrm{C}$. For most $\delta \mathrm{T}_{2 \mathrm{x}}$ values, the addition of a positive 


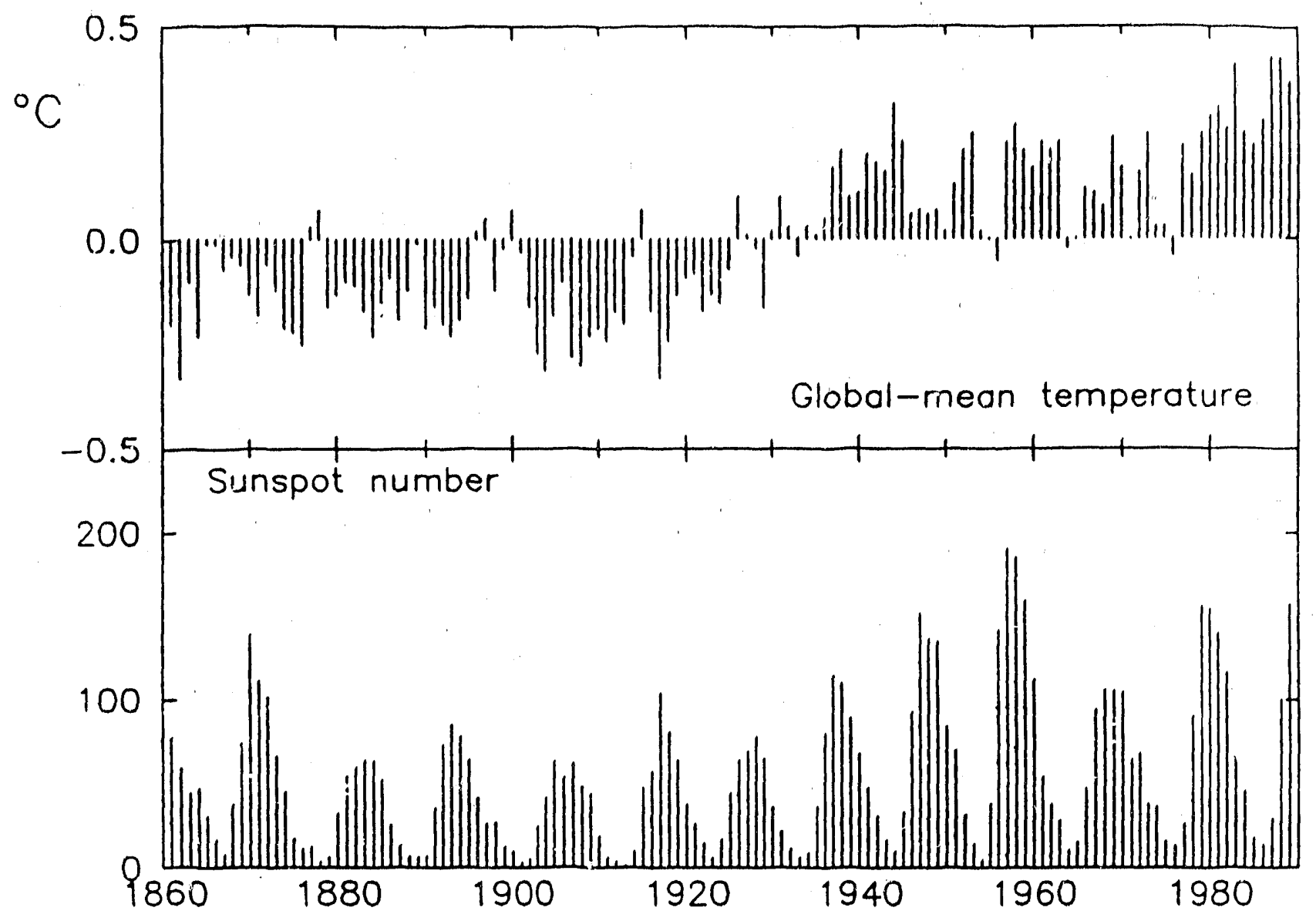

Figure 4

Global-mean surface air temperature, annual values expressed as departures from the 1861-1989 mean, and annual mean sunspot numbers. 


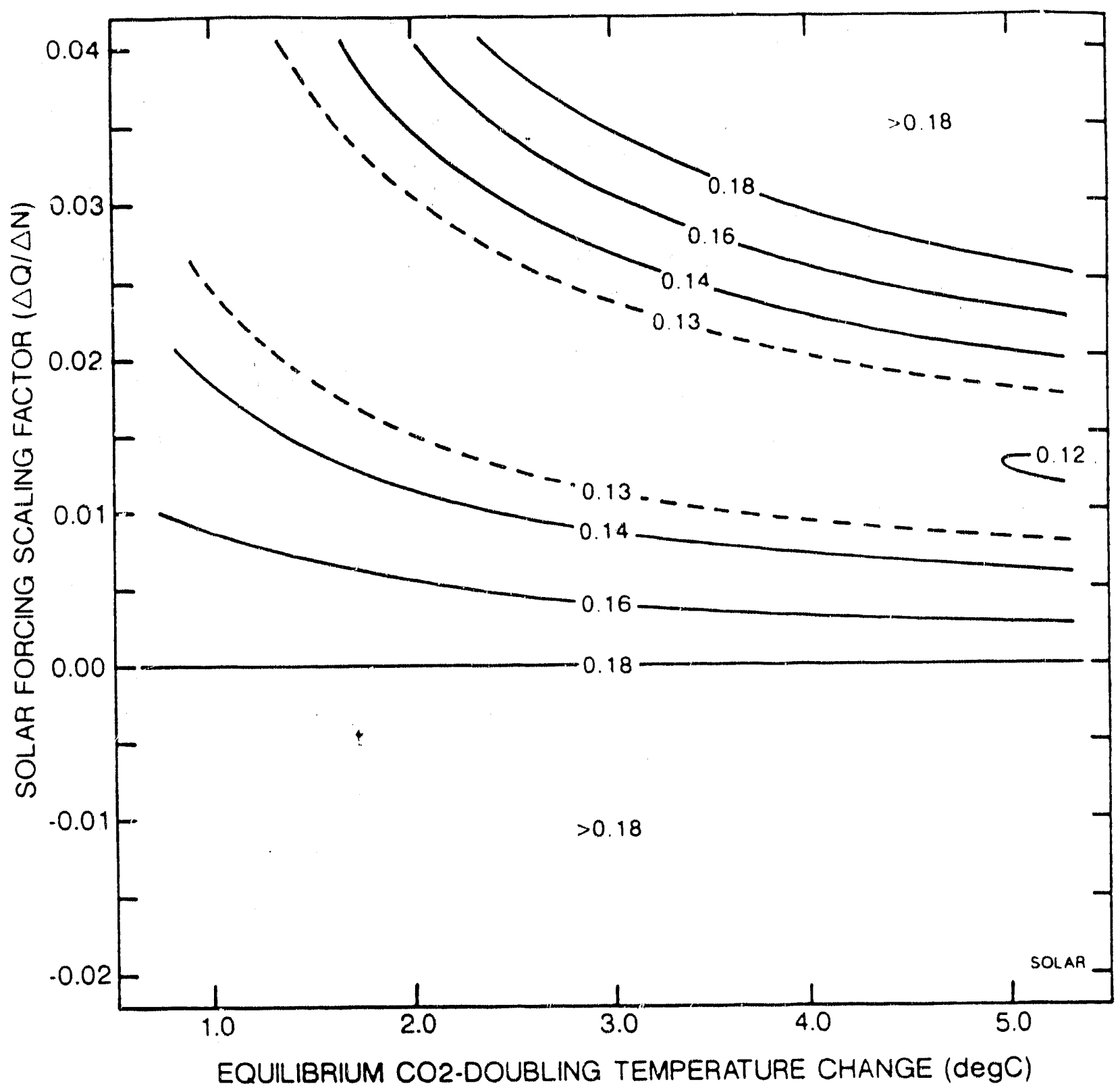

Figure 5

Variation of the root mean square error, $E_{\text {rme }}$, with the solar forcing scaling factor, $B$, and the climate sensitivity, $\Delta^{T}{ }_{2 x} ;$ solar forcing alone. Contours are not plotted when $E_{\text {rme }}$ exceeds the standard deviation of the observed data $\left(0.18^{\circ} \mathrm{C}\right)$. 
solar contribution (i.e., $B>0.0$ ) results in a higher $E_{\text {Tms }}$ than is the case when the solar component is zero. The only improvement in fit for a positive solar contribution occurs for $\delta \mathrm{T}_{2 \mathrm{x}}<2.0^{\circ} \mathrm{C}$. $\mathrm{E}_{\mathrm{Tms}}$ reaches a minimum when $\beta \approx 0.004$ for $\delta \mathrm{T}_{2 \mathrm{x}}=1.5^{\circ} \mathrm{C}$ and when $B=0.016$ for $\delta T_{2 x}=1.0^{\circ} \mathrm{C}$. These values of $B$ are four and sixteen times, respectively, that suggested by the satellite data. This discrepancy must be explained if the solar contribution is to be justified. In any event, the inclusion of a non-zero solar forcing term in these cases results in little improvement in $\mathrm{E}_{\mathrm{Tms}}$. In terms of percentage variance explained, the improvement amounts to $5 \%$ of the variance of the observed data at most (Table 1). This is much less than implied by Reid in his analysis of combined greenhouse and solar forcing.

Table 1: The best-fit combinations of the climate sensitivity, $\delta \mathrm{T}_{2 \mathrm{x}}$, and the solar scaling forcing factor, $B$, with the associated error variances. Cases are defined by the $\delta \mathrm{T}_{2 \mathrm{x}}, B$ combination. Satellite data suggest that $B$ lies around 0.001 . The error variance is given in relative terms as the ratio, variance remaining after subtracting the modelled from the observed temperatures to original variance in the observed data.

$\begin{array}{lllcl}\text { Case } & \text { Forcing } & \delta \mathrm{T}_{2 \mathbf{x}} & \text { Solar forcing } & \text { Error } \\ & & \left({ }^{\circ} \mathrm{C}\right) & (\boldsymbol{B}) & \text { Variance (\%) } \\ 1 & \text { Solar alone } & 5.0 & 0.012 & 44.3 \\ 2 & & 1.0 & 0.038 & 45.1 \\ 3 & \text { Greenhouse alone } & 1.5 & 0.000 & 40.2 \\ 4 & \text { Solar and } & 1.0 & 0.016 & 35.0 \\ 5 & \text { Greenhouse } & 1.5 & 0.004 & 38.4\end{array}$

Our results contradict Reid's assertion that a reasonable fit can be obtained using both greenhouse and solar forcing with $\beta=0.017$ (equivalent to his optimal $\alpha$ value for combined forcing) and $\delta \mathrm{T}_{2 \mathrm{x}}=2.5^{\circ} \mathrm{C}$. For this climate sensitivity, our best fit occurs when $B=-0.004$, implying that higher sunspot numbers are associated with cooling not warming. In fact, the 
lowest $E_{\mathrm{rms}}$ consistently occurs when $B$ is negative for $\delta \mathrm{T}_{2 \mathrm{x}}>2.0^{\circ} \mathrm{C}$ (cf. Figure 6), suggesting that low-frequency solar variability may have offset greenhouse warming over the past 100 years.

Our findings should not be considered definitive proof that enhancement of the greenhouse effect has accounted for a substantial proportion of the warming trend observed over the past 100 years. Nor should too much weight be attached to the best-fit value of the slimate sensitivity (viz. $\delta \mathrm{T}_{2 \mathrm{x}}=1.5^{\circ} \mathrm{C}$ ) identified here for greenhouse forcing alone. To isolate the greenhouse signal and determine the climate sensitivity, other factors, such as internallygenerated climate variability and the effect of additional external forcing agents, would have to be taken into account.

It can be concluded that, since the mid-19th century, the influence of the enhanced greenhouse effect on global-mean temperature has almost certainly dominated over the direct influence of solar variability. For solar variability to have been an important contributing factor, past low-frequency variations in solar irradiance would have to have been far greater than recent satellite studies indicate. There is no firm evidence to support this contention. Compared to the well-established observational and theoretical basis supporting the theory of greenhouse forcing, the case for a solar influence on recent changes in global climate is speculative in the extreme.

\section{International Activities}

In 1989-90, all investigators were deeply involved in major international research activities. These include the US/USSR data exchange discussions in Moscow, meetings of the InterGovernmental Panel on Climatic Change (I.P.C.C.) in the U.K. and the U.S., and work on the US/USSR report Prospects for Future Climate. These efforts have involved major writing and reviewing assignments, the results of which are not always apparent since they are incorporated into large multi-authored reports. Nevertheless, these committments consumed large amounts of the investigators' time in 1989-90. The I.P.C.C. report will be presented by 


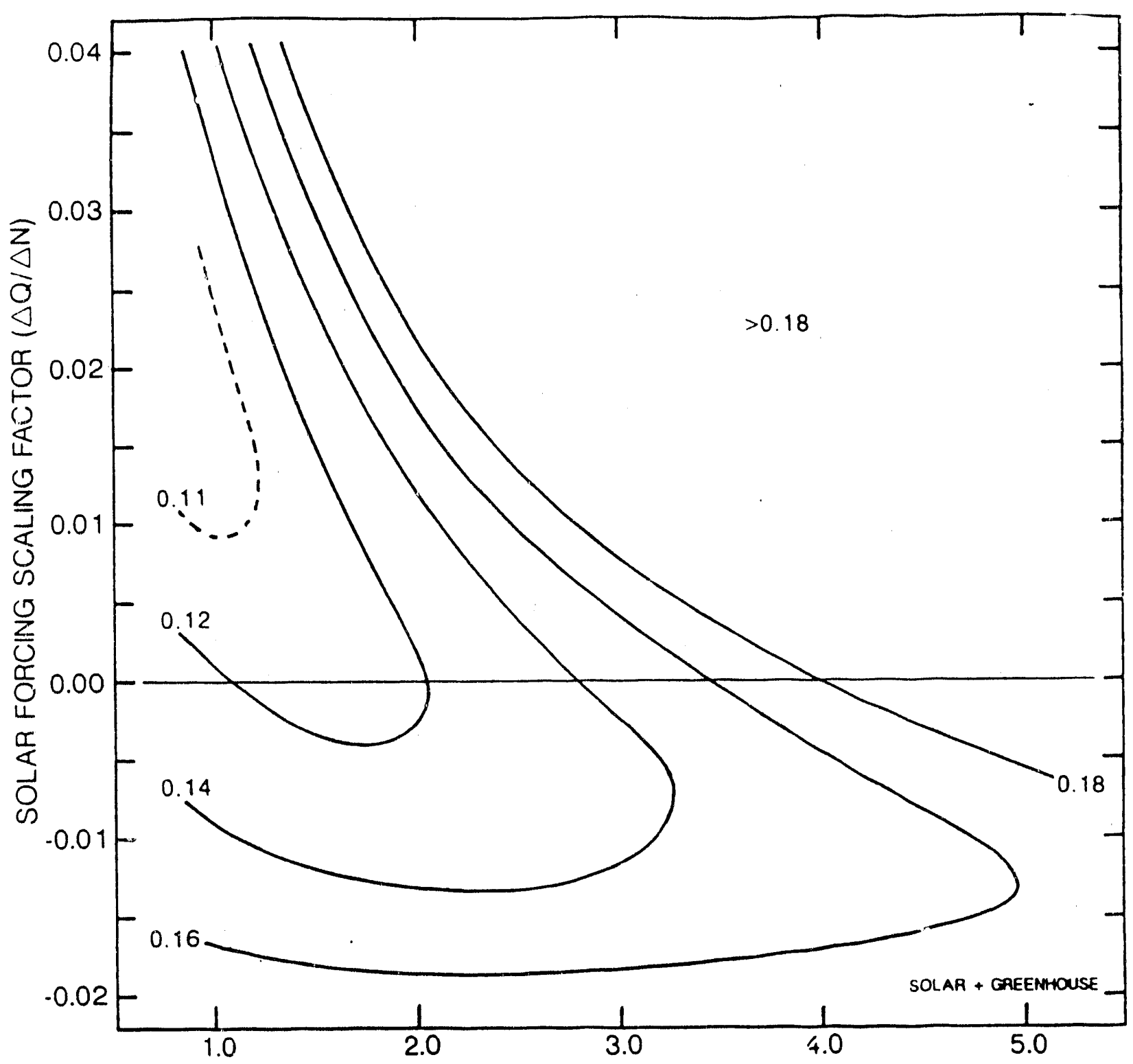

EQUILIBRIUM CO2-DOUBLING TEMPERATURE CHANGE (degC)

Figure 6

Variation of the root mean square error, $E_{r m e}$, with the solar forcing scaling factor, $B$, and the climate sensitivity, $\Delta^{\top}{ }_{2 x}:$ greenhouse plus solar forcing. Contours are not plotted when $E_{\text {rma }}$ exceeds the standard deviation of the observed data $\left(0.18^{\circ} \mathrm{C}\right)$. 
Project Leaders at the 2nd World Climate Conference in Geneva in November 1990 and form the basis for discussions at the United Nations in December.

The US/USSR data exchange discussions have resulted in important additions to our data sets for Soviet territorial regions. The US/USSR report, Prospects for Future Climate (edited by M.C. MacCracken, A.D. Hecht, M.I. Budyko and Y.A. Izrael) will be published late in 1990.

In addition to these activities, Bradley and Jones initiated a major project to edit a book on climatic variations over the past few centuries entitled Climate Since A.D. 1500. It will be published in 1991 by Unwin Hyman. Four chapters by Bradley and Jones are included in the volume. 


\section{REFERENCES}

Bradley, R.S. and Groisman, P. Ya., 1990 Continental scale precipitation variations in the 20ih century. In: B. Sevruk (ed.) Precipitation Measurement. Swiss Federal Institute of Technology, Zurich, p. 499-504.

Bradley, R.S., Diaz, H.F., Eischeid, J.K., Jones, P.D., Kelly, P.M. and Goodess, C.M., 1987. Precipitation fluctuations over Northern Hemisphere land areas since the mid19th century. Science, 237, 171-175.

Diaz, H.F., Bradley, R.S. and Eischeid, J.K., 1989. Precipitation fluctuations over global land areas since the late 1800s. Journal of Geophysical Research, 94, 1195-1210.

Eischeid, J.K., Diaz, H.F., Bradley, R.S. and Jones, P.D., 1990. A Comprehensive. Precipitation Data Set for Global Land Areas. Department of Energy Technical Report (in preparation).

Folland, C.K., Parker, D.E. and Kates, F.C., 1984. Worldwide marine temperature fluctuations, 1856-1981. Nature, 310, 670-673.

Foukal, P. and Lean, J., 1990. An empirical model of total solar irradiance variation between 1874 and 1988. Science, 247, 556-558.

Kelly, P.M. and Wigley, T.M.L., 1990. The relative contribution of greenhouse and solar forcing to observed trends in global-mean temperature. Nature, in press.

Reid, G.C., 1987. Influence of solar variability on global sea surface temperatures. Nature, 329, 142-143.

Wigley, T.M.L. and Raper, S.C.B., 1987. Thermal expansion of sea water associated with global warming. Nature, 330(6144), 127-131.

Wigley, T.M.L. and Kelly, P.M., 1990. Holocene climatic change, ${ }^{14} \mathrm{C}$ wiggles and variations in solar irradiance. Phil. Trans, Roy. Soc. Lond., A330, 547-560.

Wigley, T.M.L. and Raper, S.C.B. 1990. Climatic change due to solar irradiance changes. Geophys. Res. Lett., in press. 
APPENDIX 1 


\section{A Comprehensive Precipitation Data Set Over Global Land Areas}

Prepared by:

Jon K. Eischeid and Henry F. Diaz

CIRES, University of Colorado and Environmental Research Laboratories, NOAA, Boulder, $\mathrm{CO}$

Raymond S. Bradley

University of Massachusetts

Amherst, MA

Phillip D. Jones

Climatic Research Unit

University of East Anglia

Norwich, U.K.

Under Contract No. DE-FG02-89ER69017 


\begin{abstract}
An expanded and updated compilation of long-term station precipitation data, togethe: with a new set of gridded monthly mean fields for global land areas are described. The present data set contains 4821 station records of monthly total precipitation, covering the period from the mid-1800s to the late 1980s. Comparisons of these data with other global-scale precipitation climatologies are presented, together with three indices of long-term precipitation variations over the global land areas. The station data were individu.lly tested and visually inspected for the presence of spurious trends, jumps and other measurement biases. The quality control procedure which was used to check the station records for non-climatic discontinuities and other biases is detailed. We als $\mathrm{J}$ discuss some of the problems which typically contribute to potential inhomogeneities in precipitation records.
\end{abstract}


Introduction

The possible impacts of global warming from increases in radiatively active irace gases has led to renewed interest fer information the nature of hydrological variability on spatial scales ranging from smaller "regional" averages (Diaz and Eischeid, 1990) to "hemispheric" and "global" indices (Bradley, et al., 1987; Diaz, et al., 1989; Vinnikov, et al., 1990). These studies, as with many others, have relied on compilations of station data from various sources (e.g. World Weather Records, Monthly Climatic Data for the World). Bradley, et al. (1985, 1987) syfhthesized these data sources to form a Northem Hemisphere climatic data bank. Diaz, et al. (1989) added considerably to this data set, while also including data for the Southem Hemisphere.

In this technical report, we describe the extension of the set of monthly precipitation records used by Diaz, et al. (1989). To illustrate the use of such data, we will detail the construction of a gridded data set used to describe the climatology and the secular variability of global-scale precipitation. Prior to inclusion into the expanded data set, all individual precipitation series were examined for possible inhomogeneities caused by a variety of (nonclimatic) influences. The data sources used in the compilation and subsequent details of the homogeneity assessment are described below. The derivation of a gridded data set and brief comparisons with previous work is presented.

\section{Data Sources}

Compilation of the data set represents an extension of the monthly station records used in previous analyses (Bradley, et al., 1987; Dikz, et al., 1989) and initially documented by Bradley, et al. (1985). Improvements in coverage occur in every continental region of the globe due, in part, to changing the reference period (a common period required of all station records for inclusion into the data set) from 1921-1960 to 1951-1970. With the addition of 
new data from sources described below, more stations are present for the 1951-1970 period than for the previous interval. Additionally, this period coincides with the one used in the compilation of hemispheric temperature indices by Jones, et al. (1986a, b), and therefore it is useful for comparative purposes.

Data from the original Department of Energy (DOE) Climatic Data Set for the entire globe has been supplemented with a number of additional data sources. These include the latest version of the World Monthly Surface Station Climatology (WMSSC) available from the National Center for Atmospheric Research (NCAR), and data acquisitions by the Climatic Research Unit, UEA with particular improvements in coverage over Airica. Improvements in coverage over North America include the addition of over 600 stations in the United States from the United States Historical Climatology Network (HCN, Quinlan, et al., 1987) and 225 long-term Canadian station records (updated through 1989) from the Atmospheric Environment Service (AES) of Canada. All stations over the US, where possible, were updated through 1989 with data supplied by the National Climatic Data Center (NCDC) in Ashev/ille, North Carolina. Further improvements in spatial coverage have also been made over Asia particularly over the Soviet Union (223 long-term station, many beginning prior to 1900), for the Peoples Republic of China (205 stations, 38 of which begin before or during the 1920's, supplied by Congbin Fu of Academia Sinica), and for Australia (from data supplied by M. Coughlan of the Australian Bureau of Meteorology). A few other stations have been added by us from various manuscripts or published sources.

\section{Station Homogeneity Assessment}

Reasons for Station Homogeneities

There are four principal reasons for discontinuities in station data that are non-climatic in origin. These include: 
(1) changes in station location (elevation or position);

(2) changes in instrumentation;

(3) changes in recording practices, such as observation times and methods used to calculate snowfall in terms of its equivalent depth of water; and

(4) changes in the environment around the recording site, particularly with reference to urban growth. Many of the implications and the resultant problems associated with these factors are discussed in some detail in several papers in Sevruk, ed. (1989).

\section{Effects}

A station's representativeness of the lical climate can be altered due to a change in the station's location. A change in the station's elevation can have profound impacts on the homogeneity of the record; in topographically diverse areas the problem is compounded. Additionally, in recent years, many stations have been moved from urbanized areas to surrounding less urbanized or rural areas (often airports). This type of station move can be critical to observations since pollutants generated from the urban center help to increase precipitation downwind from the metropolitan center (METROMEX, 1981). Even if a station had an ideal exposure at the beginning of the record and was never moved, its exposure may have deteriorated over time due to the construction of nearby buildings or the natural growth of trees (Bradley, 1976). However, although these effects have been demonstrated in specific cases for large urban areas and a few rural stations, they are in general difficult to quantify being highly dependent on the local climate and the exact location of the recording station relative to the spatial pattem of the particular city (Jones, et al., 198.5).

The unavoidable improvement of measuring techniques and instrumentation is likely the single greatest source of bias in a long-term precipitation records. Systematic errors may be 
induced due to the modifying effects of wind on the gauge orifice (Folland, 1988), and wetting of inner walls and evaporation of accumulated water (Sevruk and Klemm, 1989). Such errors will vary considerably according to the type of precipitation gauge used. As the type of gauge used varies from one country to the next, this contributes greatly to the inhomogeneity of precipitation time series over large continental-scale regions.

Another important source of bias are changes over time in recording practices, particularly with regard to reporting the water equivalency of frozen precipitation (Goodison, 1981; Karl et al., 1989; Vinnikov et al., 1990).

Given the above factors, all of which are capable of inducing biases and discontinuities in precipitation time series, an assessment of the homogeneity of each station's time series was undertaken prior to inclusion in the data set.

\section{Assessment of Homogeneity}

In practice, the evaluation of homogeneity is a formidable task when dealing with a large number (approximately 6000) of stations. The use of information contained in a station's history as a guide for potential errors is difficult for several reasons. In many cases, published station histories are incomplete particularly with regard to the type of instrumentation used. Site changes are often documented (though urbanization or growth around the site is not) but, as Jones, et al. (1985) point out, documented site changes give a pessimistic view of the potential homogeneity of a station's data; it is not reasonable to assume that a change in the station's homogeneity has occurred merely because the measurment site changed or was altered in some way. Furthermore, an exhaustive examination of station history information is precluded by the simple fact that the information is seldom published.

A search for trends and/or discontinuities in station differences by comparing records from 
neighbouring stations is not without problems. Given the global scope of this project and the highly localized nature of precipitation, the difficulty of acquiring a sufficient number of stations in close proximity to each other makes highly detailed studies of this nature impractical (in cases where outliers could not be explained by mismatched units or keypunch errors neighbouring stations were used to verify/discard a precipitation event). The procedure for the evaluation of homogeneity was therefore a compromise between practical considerations and the desire for a consistent quantitative technique which could be applied to each station. The method we have chosen is a sequential version of the Mann-Kendall rank statistic in conjunction with visual inspection of the time series which were flagged by this procedure.

Initially, each station was inspected for outliers by flagging data values that were twice as large as their respective monthly means. Suspected outliers were either verified, corrected, or replaced with the long-term monthly median. Verification was accomplished by inspection of neighbouring stations for the appropriate month/year. Correctable outliers were commonly the result of keypunch errors or the use of the wrong units (e.g. values in centimeters as opposed to millimeters).

For all stations, after the removal of outliers, the Mann-Kendall rank statistic was calculated for each monthly time series. This test is based on the fact that, under the hypothesis of no change, the succession of values for given month (or year) must be independent and that the probability distribution must always remain the same (simple random series). For each term $X_{1}$ of a series of $N$ terms, the number, $M_{1}$, of terms preceding it such that $X_{1}>X_{t-1}$ is computed and the sum $d_{N}$ is found as (Mann, 1945; Kendall, 1970; Goossens and Berger, 1987):

$$
\mathrm{d}_{\mathrm{N}}=\sum_{\mathrm{i}=1}^{\mathrm{N}} \mathbf{M}_{\mathrm{i}}
$$

For sufficiently large $N\left(N\right.$ being the length of the monthly series), $d_{N}$ has a Gaussian normal 
distribution with an expected value $E\left(d_{N}\right)=N(N-1) / 4$, and variance given by $\operatorname{var}\left(d_{N}\right)=N(N-1)(2 N+5) / 72$. The computed values of $d_{N}$ are then tested for significance usirg a two-tailed significance test. The null-hypothesis (no change in ranks through time) is rejected for large values of $u\left(d_{N}\right)$ given by Goossens and Berger, 1987:

$$
u\left(d_{N}\right)=\left(d_{N}-E\left(d_{N}\right)\right) /\left(\operatorname{var}\left(d_{N}\right)\right)^{1 / 2}
$$

The critical value of $u\left(d_{N}\right)$ is then found by means of a table (in this application IMSL (1984) subroutines were utilized) for a normal reduced variable, the null-hypothesis is accepted or rejected at the $95 \%$ confidence level. If $u\left(d_{N}\right)$ exceeded the critical value, it was assumed a significant increase $u\left(c_{N}\right)>0$ or decrease $u\left(d_{N}\right)<0$ in the monthly precipitation series had taken place, and the particular station was flagged for further analysis.

At this point we wish to locate the approximate beginning of any suspected discontinuity. In this regard, a sequential version of the Mann-Kendall ter: (initially proposed by Sneyers, 1963; Sneyers, 1975 and applied by Goossens and Berger, 1987 and Sneyers, et al., 1989) allows the detection of the approximate inception of any change. The test is based on the computation of all $u\left(d_{1}\right)$, where $1<i<N$, through a formula similar to (1). The statistic, $d_{i}$, is given for the first $\mathrm{i}$ terms by:

$$
d_{1}=m_{1}+m_{2}+\ldots+m_{1}
$$

An example of this approach is shown in Figure 1 for the month of June for a station located in Gorlitz, East Germany. It shows that the values of $u\left(d_{1}\right)$ are significantly negative $(<1.96)$ on and after the 43rd observation (i.c. 1893). This series thus represents a significani change toward lower precipitation values. However, while the application of this method reveals a significant change in 1893, careful examination of the actual monthly values (Figure 1) indicates a sharp break in the data beginning in 1889 . For this reason a combination of the sequential version of the Mann-Kendall rank statistic and visual exaination of the plotted precipitation values was used in order to delineate true discontinuities. Rather than attempt 
to adjust/correct data prior to any discontinuities, for reasons outlined at the beginning of this section, the offending data were eliminated from the station's record.

\section{Results of the Station Homogeneity Assessment}

Initially, 5858 station orecipitation records were compiled from a variety of sources with the period of best data coverage in the interval 1951-1970. For stations to be included in the present data set we required that at least 15 years of data be present between 1951-1970. Approximately $17 \%$ of 5858 stations were eliminated because of station records that were too short. The remaining 4835 were analyzed for discontinuities as described above. Of these, $33 \%$ exhibited a significant change/trend in at least one of the respective station's monthly series. Further analysis indicated 45 stations in which a discontinuity was clearly the result of aon-climatic factors and all or portions of each record were excised. After the deletion of sections of data for these 45 stations, 14 were found to be too short given the preceding length requirement and were eliminated in their entirety (31 were retained, but without the questionable data). The present data set thus includes 4821 stations which are listed in Appendix A, and whose locations are shown graphically in Figure 2a. The distribution with time of the number of stations available by year is shown in Figure $2 b$, while the number of stations located in $90^{\circ}$-longitude/latitude sectors is summarized in Table 1 . The figures illustrate the significant gap in coverage present in the South Pacific Ocean, due to the existence of large expanses of open ocean.

As in previous studies, the spatial distribution of station records is not uniform with time, being concentrated in Europe, the United States and over the Indian subcontinent in the late 1800 's (see Fig. 3), in the Northem Hemisphere, and over portions of Australia, New Zealand and a few locations in South America. By the early years of this century, however, a significant improvement in coverage can be noted, such that 'global-scale' averages jecome 
reasonably stable from that time on. Nevertheless, the small number of stations avalable in some areas (Fig. 3), provides a good rationale to assess long-term precipitation variations within a regional context as well (see Diaz and Eischeid, 1990).

The small number of stations in which discontinuities were identified is likely a result of initial quality control procedures applied to many of the station records (see Bradley, et al., 1985, 1987; Diaz, et al., 1989; Eischeid, 1986). Station data from the US Historical Climatology Network had been exhaustively checked as part of that project (Quinlan, et al. 1987) and, the Russian and Chinese station records supplied to us were considered "reliable" and likely underwent some form of quality control. The same is true for the Canadian data and essentially true for the Australian data as well. Nevertheless, some station records considered to be "homogenous" may still contain spurious trends due to systematic errors associated with changes in instrumentation applicable across national networks, which thus renders pairwise comparisons of station records ineffective. As noted earlier, problems associated with conversion of frozen precipitation to water equivalents presents one of the most serious problems in data quality. To a large extent, such errors will be minimized by aggregation into large scale averages. Precipitation changes at very large spatial scales is the subject emphasized in this report.

\section{Gridding}

The specification of mean precipitation fields of global precipitation have been made by many researchers (e.g. Unesco, 1978; Jăeger, 1983 and Legates and Wilmott, 1990) and is undertaken here for comparative purposes. Previous studies of large-scale changes have been hamrered by the lack of a data base that is geographically and temporally extensive (Gruza and Apasova, 1981; Bradley, et al., 1987; Diaz, et al., 1989, and Vinnikov, et al., 1990). Morenver, methodological problems related to the high spatial variablity of precipitation make 
it difficult to construct indices that are not dominated_ther with either very high or very low amounts of precipitation. We address this problem by using probabilistic and empirical methods to characterize mean precipitation and compare/contrast the results. Because of the irregular spatial distribution of station records, the data are interpolated onto a regular grid to avoid unduly weighting global averages by small areas with many long-term records.

Prior to gridding, three estimates of station variability are calculated from annual precipitation totals. The first is simply annual departures from the reference period mean. The second is a standardized version of the first, where annual precipitation values are decribed as percentage departures from the reference period mean. The third is probabilistic in nature and attempts to account for the fact that precipitation frequency distributions are generally non-normally distributed. The procedure was employed by Bradley, et al. (1987) and Diaz, et al. (1989) and involves estimation of annual precipitation probabilities using the gamma distribution. Previous work has shown that precipitation probabilities can be estimated with good precision by the gamma distribution (Ropelewski and Jalickee, 1984). The gamma distribution is a two-parameter frequency distribution given by:

$$
f(x)=\left(1 / \beta^{\gamma} \cdot \Gamma(\gamma)\right) \cdot x^{71} \exp (-x / \beta) ; \beta>0 ; \gamma>0
$$

where $x$ is the random variable (precipitation amount), $\gamma$ and $\beta$ are the appropriate shape and scale parameters, and $\Gamma$ is the ordinary gamma function of $\gamma$. The shape and scale parameters are estimated by the technique of Thom (1958). The gamma function is fitted to each station series af annual precipitation totals after which the amounts are converted to equivalent probability values or percentile points of the gamma distribution (a number between 0 and 1). Hence a value of, say, 0.40 for a given year implies that the precipitation amount for that period falls in the lowest $40 \%$ of the historical record, assuming that its probability distribution is properly described by a gamma function.

The three indices (as well as long-term monthly and annual means) were objectively 
interpolated onto a $4^{\circ}$ latitude by $5^{\circ}$ longitude grid extending from $80^{\circ} \mathrm{N}$ to $60^{\circ} \mathrm{S}$ (interpolation methods used in the past are discussed in Jones, et al., 1982, 1985; and Bradley et al., 1987). The precipitation indices are averaged at each grid point for all stations that have this as their nearest grid point using a space-filtering technique described by Bames (1964). This procedure is given by:

$$
T_{y}=\sum_{n=1}^{N} W_{n} \cdot Y_{n}(x, y) / \sum_{n=1}^{N} W_{n}
$$

where $Y_{n}$ is the particular annual/monthly precipitation index at station location $(x, y)$ and the weight function $\mathrm{W}_{\mathrm{n}}$ is

$$
W_{n}=\exp \left(-d^{2} / 4 c\right)
$$

where $\mathbf{d}$ is the great circle distance in kilometers from the grid node $(i, j)$ to the station location $(x, y)$. The weight function constant $c$ is arbitrarily chosen to fit a particular application, and is a function of the spatial structure of the phenomena in question. In the present analysis, a value of 1000 is chosen. All available station data are used and, in order not to inflate the degree of spatial autocorrelation, precipitation values are used for interpolation at only one grid point. In situations where a grid point has only one station available the station precipitation value becomes the grid point value. It should be noted that in data dense areas the computed grid point values may have lower inter-annual variance compared with nearby grid values based on fewer stations. However, the exponential distance weighting and the effects of spatial correlation tend to minimize this problem.

The gridding $m$, chod was used to interpolate from station data to the latitude-longitude grid for the three estimates of secular precipitation variability noted earlier, and an estimate of the monthly/annual precipitation climatology. The four gridded data sets generated include: 1) monthly/annual long-term precipitation values; 2) seasonal/annual percentage departures from the mean; 3) seasonal/annual departures expressed in millimeters and; 4) seasonal/annual percentiles of the garnma distribution. 


\section{$\underline{\text { Global Climatology }}$}

Mean annual precipitation for the gridded set (hereafter DOE) is presented in Figure 4a. For comparative purposes, the estimates of mean annual precipitation from the work of Legates and Wilmott (1990) and Jăeger (1983) are also given in Figure 4b (LW) and Figure $4 c$ (JG) respectively. The broad scale features shown by the DOE estimates compare favorably in both a quantitative and qualitative sense with that of LW and JG. The DOE grid lacks measurments over most of the oceanic areas and high latitide regions of both hemispheres though, as will be shown later, this deficiency does not seriously affect the annual march of zonal precipitation. It will be shown that the annual average global precipitation estimate in the present study lies in the middle range of previous estimates.

As expected heaviest annual rainfall is present over much of the tropics. The maximum of precipitation in the latitude band comprising the Inter-Tropical Convergence Zone (ITCZ) is well represented in the equatorial central and western Pacific, especially in the region of South Pacific Convergence Zone (SPCZ). High mean annual precipitation is also shown in all three maps over the rainforest regions of Africa, South America, and Asia as well as regions of monsoonal circulation.

Very low rainfall, associated with the descending branches of the Hadley cell, for desert regions such as the Sahara, Atacama, and the Australian Outback are representative of all three grids. In both LW and JG, extension of these desert regions over adjacent oceanic areas (not a feature of the DOE grid) is related to lower sea surface temperatures due to upwelling (e.g. west coasts of South America and South Africa). Low annual precipitation owing to the rain-shadow effect on leeward sides of mountain ranges can be seen over the Himalayas, the Rockies, and the Andes. The low amounts of precipitation at high latitudes in both hemispheres is not well represented in the DOE grid though these areas contribute small 
amounts to the global mean. In general, the principal spatial features of mean annual precipitation are characterized reasonably well by this analysis. However, the DOE grid is inadequate over large areas of the world's oceans and at high latitude areas because of insufficient station records.

Representative of the annual march of precipitation is the aggregate zonal precipitation for January, July, and Annual values shown in Figure 5 for the DOE and JG grids (this information was not available for LW). Here, the DOE and JG climatologies exhibit the characteristic three-peak pattern of enhanced precipitation in the zonal westerlies and the equatorial zone. The asymmetric global distribution of land and sea gives rise to the pronounced peak in the southern hemisphere westerlies relative to similar latitudes of the northern hemisphere. The transition of rainfall from the southem tropics in January to the northern tropics in July as the sun (and maximum heating) moves northward is also well represented in both climatologies. Though similar in its pattem and timing, the JG climatology shows lower absolute amounts of precipitation, particularly in the tropics, and may have underestimated the global mean average.

The annual cycle of global precipitation is shown in Figure 6a and $6 \mathrm{~b}$ for the DOE and JG grids respectively. Peak values during the months of June, July, and August, preceded and followed by relative minima, are in tune to the annual cycle of global insolation. In all months the DOE climatology shows larger values of precipitation relative to the JG climatology. Investigation of phase and amplitude information of the annual and semi-annual harmonics also reveals differences between climatologies (Table 2). Both climatologies are dominated by the annual and semi-annual cycles, as shown by the cumulative percentage of explained variance for these two harmonics (DOE, 97\%; JG, 96\%). A notable disparity exists corsting ming the proportion of variance explained between the first and second harmonics. The most important harmonic for the JG climatology is clearly the first $(60.6 \%)$ at the expense 
of the second (35.8\%) whereas the DOE climatology actually explains more variance with the semi-annual cycle than with the anriual (50.3\% versus $46.8 \%)$. The differences between the climatologies are shown graphically by the monthly zonal means in Figure 7. The transition from southem summer to northem summer in the tropics for the JG climatology (7b) is smooth and gradual with a singular rainfall peak in northem summer. In contrast, the DOE climatology (7a) has distinct rainfall peaks in both southem and northern summer. The DOE climatology conforms better to the annual cycle of global precipitation as depicted by the climatological monthly values of Outgoing Longwave Radiation (OLR) in Figure 7c. We use the mean OLR fields as an indicator of deep convection and rainfall in the tropics $\left(30^{\circ} \mathrm{N}\right.$ $30^{\circ} \mathrm{S}$ ). The two peaks of low OLR (highest rainfall) match the semi-annual cycle of the DOE climatology on both spatial and temporal scales. The single peak of rainfall shown by the JG climatology is likely attributable to the excessive smoothing of marine grids, thus greatly eliminating the southem hemisphere rainfall peak during that hemisphere's summer (see Jăeger, 1983).

The annual average "global land area precipitation" for the DOE climatology derived here is $1033 \mathrm{~mm}$ while that of $\mathrm{LW}$ is $1123 \mathrm{~mm}$ and JG is $966 \mathrm{~mm}$. Based on other evidence (cf Kessler, 1985) Jaeger considered his estimate too low, and felt that a value of $1000 \mathrm{~mm}$ was more appropriate. He then adjusted his marine and polar grids by a factor of 1.062 to compensate for deficiencies in these areas (Jaeger, 1983). The DOE value compares avorably with LW and is also consistent with values suggested by Kessler (1985). We think that these gridded fields represent an adequate climatology of annual precipitation over land areas of the globe. An accurate precipitation climatology for the oceans will need to be constructed from satellite measurements. Such measurements for the global tropics have been made for about ten years. Insofar as the march of the annual cycle is concemed, the tropical OLR data agrees well with the data of this study. 


\section{Secular Variability of Global Annual Precipitation}

The three gridded estimates of precipitation are area averaged to form global indicles of secular precipitation variability. The global index is calculated by averaging each grid point value after being weighted by the area it represents. Weighting is achieved by multiplying grid point values by the cosine of the latitude of the grid point divided by the sum of the cosine weights used.

The spatial representativeness of computed global averages is of course dependent on the number of grid points available in any one year. The number of grid points increases between 1851 and 1950, is stable between 1951 and 1980, and thereafter drops slightly to the end of the record (1989). Despite changes in the spatial coverage, the global averages appear reliable after 1880 and extending through 1980. The general trends for the 1980's are considered reliable, though the magnitudes of the yearly estimates should be treated with caution. Prior to 1880 , yearly estimates of the global fields are less reliable.

Resultant global averages are shown in Figure 8 for the percentage deviations from the mean (8a), the millimeter departures (8b) and the percentiles of the gamma distribution (8c) time series. All reveal similar features on decadal to longer time scales. On interannual time scales, differences do arise but, in general, the characteristics of anomalous global precipitation are consistent between the time series from one year to the next. The statistical relationships, shown by the value of the correlation coefficient, $R$, in Figure 9, support this observation. The dimensional and normalized estimates are likely to be more sensitive to changes in the number of grid point values used to calculate the average. Interannual variablity is thus higher in these two indicles relative to the probablistic series and the correlation coefficient between the two empirical estimates is reduced $(R=.71$, Fig. 9a). The stability of the probabilistic series relative to the empirical estimates is apparent in the scatter diagrams of 
Fig.'s $9 \stackrel{b}{a}$ and $9 \mathrm{c}$ (the percent deviations versus the probabilities and the millimeter departures versus the probability time series, respectively). Values of $R$ are higher (.85 and .84) and the residual variance is much smaller than that shown in Figure 9a. We also compute the following quantity as a measure of each seriıs interannual variability:

$$
\mathrm{IAV}=\left[(\mathrm{n}-1)^{-1} \Sigma_{h=1}{ }^{\mathrm{n}}\left(\mathbf{R}_{\mathrm{H}+1}-\mathbf{R}_{\mathrm{L}}\right)^{2} / \sigma^{2}\right]^{1 / 2}
$$

where $\mathrm{N}$ is the length of the time series and $\sigma^{2}$ is the variance. The computed values confirm that the probabilistic series $(8 \mathrm{c})$ exhibits the lowest interannual variability with a value of 1.07 ; the percentage deviations from the mean (8a) has the largest measure (IAV=1.20), with IAV=1.11 for the millimeter departure series (8b).

A salient feature of each of the annual series is the tendency for precipitation values to be above or below the mean for extended periods of time. Values decrease sharply from the early 1890 's to the early 1900 's after which values are pretty much below normal to the mid 1940 's, altough this extended dry period exhibits considerable interannual variability. Following this dry period, an increase in precipitation occurs from the mid 1940's to peak values around 1955. Although values remain generally above normal, a slight downturn until the late 1960's is followed by an increase to another peak in the mid 1970's, and by a retum to drier conditions by the mid 1980 's.

In summary, the three precipitation indices reproduce similar features of the secular variability of the annual precipitation for global land areas. The probabilistic series has the smallest amplitude and is the most stable as the number of gridpoints available to form the global mean changes through time. The downside to the percentiles is that they are difficult to interpret given no other information. Surprisingly, the normalization of precipitation estimates (percentage deviations from the mean) exhibits the largest interannual variability, likely attributable to the large variance typical of many station precipitation records. The millimeter departure series shows a good correspndence with the percentile series and has the 
advantage of interpretability. 


\section{$\underline{\text { References }}$}

Bames, S.L., 1964: A technique for maximising details in numerical weather map analysis. Jour. Appl: Meteor., 3, 396-409.

Bradley, R.S., 1976: Precipitation History of the Rocky Mountain States. Westview Press, Boulder, $\mathrm{CO}, 334 \mathrm{pp}$.

, P.M. Kelly, P.D. Jones, C.M. Goodess, and H.F. Diaz, 1985: A climatic data bank for the Northem Hemisphere land areas, 1851-1980. DOE Technical Report No. TR017, U.S. Dept. of Energy Carbon Dioxide Research Division, Washington. D.C., 335 pp.

, H.F. Diaz, J.K. Eischeid, P.I. Jones, P.M. Kelley, and C.M. Goodess, 1987: Precipitation fluctuations over Northern Hemisphere land areas since the mid-19th century. Science, 237, 171-175.

Diaz, H.F., R.S. Bradley, and J.K. Eischeid, 1989: Precipitation fluctuations over global land areas since the late 1800's. J. Geophivs. Res., 94, 1195-1210.

and J.K. Eischeid, 1990: Secular changes in regional precipitation over global land areas. J. Geophys. Res., submitted.

Eischeid, J.K., 1986: Precipitation variations over Northern Hemisphere land areas and major wheatproducing regions: 1851-1980. Unpublished Masters Thesis, Univ. of Massachusetts/Amherst, Amherst, MA, 195 pp.

Folland, C.K., 1988: Numerical models of the raingauge exposure proble, field experiments and an improved collector design. Q.J.R. Met. Soc., 114, 1485-1516.

Goodison, B.E., 1981: Compatibility of Canadian snowfall and snow cover data. Water Resorc. Res., $17,893-900$.

Goosens, C. and A. Berger, 1987: How to recognize an abrupt climatic change ? In, Abrupt Climatic Change, Evidence and Implications, W.H. Berger and L.D. Labeyrie (Eds.), D. Reidel Publ. Co., pp. 31-45.

Gruza, G.V. and Y.G. Apasova, 1981: Climatic variability of the Northem Hemisphere precipitation amounts. Meteor. an Gidrol., 5, 5-16.

IMSL, 1984: Intemational Math and Statistics Library, Ed. 9.2, Houston, TX.

Jäeger, L., 1983: Monthly and areal patterns of mean global precipitation. In, Variations in the Global Water Budget, A. Street-Perrot, et al., (Eds.), D. Reidel Publ. Co., pp. 129-140.

Jones, P.D., T.M.L. Wigley, and P.M. Kelley, 1982: Variations in surface air temperatures: Part 1. Northem Hemisphere, 1881-1980. Mo. Wea. Rev., 110, 59-72.

, S.C.B. Raper, B. Santer, B.S.G. Cherry, C.M. Goodess, P.M. Kelly, T.M.L. Wigley, R.S. Bradley, and H.F. Diaz, 1985: A grid point surface air temperature data set for the Northern Hemisphere. DOE Technical Report No. TR022, U.S. Dept. of Energy Carbon Dioxide Research Division, Washington. D.C., 251 pp. 
S.C.B. Raper, R.S. Bradley, H.F. Diaz, P.M. Kelley, and T.M.L. Wigley, 1986a: Northern Hemisphere surface air temperature variations, 1851-1984. Jour. Clim. Appl. Meteor., 25, 161 179.

S.C.B. Raper, and T.M.L. Wigley, 1986b: Southem Hemisphere surface air temperature variations, 1851-1984. Jour. Clim. Appl. Meteor., 25, 1213-1230.

Kendall, M.G., 1970: Rank Correlation Methods, Griffin, London, 202 pp.

Kessler, A., 1985: Heat balance climatology. In, World Survey of Climatology, Vol 1a, H.E. Landsburg (Ed.) Elsevier, New York, 224 pp.

Legates, D.R. and C.J. Willmott, 1990: Mean seasonal variability in gauge-corrected, global precipitation. Inter. J. Climatol., 10, 111-127.

Mann, H.B., 1945: Non-parametric test of randomness against trend. Econometrika, 13, 245-259.

METROMEX, 1981: METROMEX: A review and summary. S.A. Chagnon (Ed.) Meteor. Mono., 18, Amer. Meteor. Soc., Boston, MA, 181 pp.

Quinlan, F.T., T.R. Karl, and C.N. Williams, Jr., 1987: United States historical climatology network (HCN) serial temperature and precipitation data. NDP-01 ${ }^{\circ}$, Carbon Dioxide Information Analysis Center, Oak Ridge National Laboratory, Oak Ridge, Tcnn, 250 pp.

Ropelewski, C.F. and J.B. Jalickee, 1984: Estimating the significance of seasonal precipitation amounts using approximations of the inverse gamma function over an extended range. Preprints, Eighth Conference on Probability and Statistics in the Atmospheric Sciences, Amer. Meteor. Soc., Boston, MA.

Sevruk, B., (Ed.), 1989: Precipitation Measurment. Proc. of Workshop on Precipitation Measurment St. Moritz, Swiss Federal Inst. Tech. ETH Zentrum CH-8092, 584 pp.

Sevruk, B. and S. Klemm, 1989: Types of standard precipitation gauges. In, Precipitation Measurment. Proc. Workshop on precipitation measurment St. Moritz, B. Sevruk, (Ed.), Swiss Federal Inst. Tech, ETH Zentrum CH-8092, pp. 227-232.

Sneyers, R., 1963: Sur la determination de la stabilite des series climatologiques. In, Proc. UNESCOWMO Symposium of Changes of Climate, UNESCO Arid Zone Research Series, 20, Unesco, Paris, pp. $37-44$.

1975: Sur l'analyse statistique des series d'observations. WMO Tech. Note, $\underline{143}$, Geneva Switzerland.

M. Vandiepenbeeck, G. Demaree, and R. Vandierde, 1989: The homogenization of the series of monthly totals of rainfall in Brussels-Uccle (1833-1989) and the assessment of climate change. In, Precipitation Measurement, Proc. Workshop on Precipitation Measurement St. Moritz, Swiss Federal Inst. Tech., ETH Zentrum CH-8092, pp. 49-54.

Unesco, 1978: World water balance and water resources of the earth. Unesco Series Studies and 
Reports in Hydrology, 25, Leningrad, $663 \mathrm{pp}$. 
Table 1

Number of Stations by $90^{\circ}$ Sectors

$0-90^{\circ} \mathrm{E} \quad 90^{\circ} \mathrm{E}-180^{\circ} \quad 180^{\circ}-90^{\circ} \mathrm{W} \quad 90^{\circ} \mathrm{W}-0^{\circ}$ Total

$\begin{array}{lrrrrr}\text { Northem Hemisphere } & 899 & 492 & 1147 & 862 & 3400 \\ \text { Southem Hemisphere } & 631 & 405 & 30 & 355 & 1421\end{array}$

Table 2

Annual Cycle (First Harmonic)

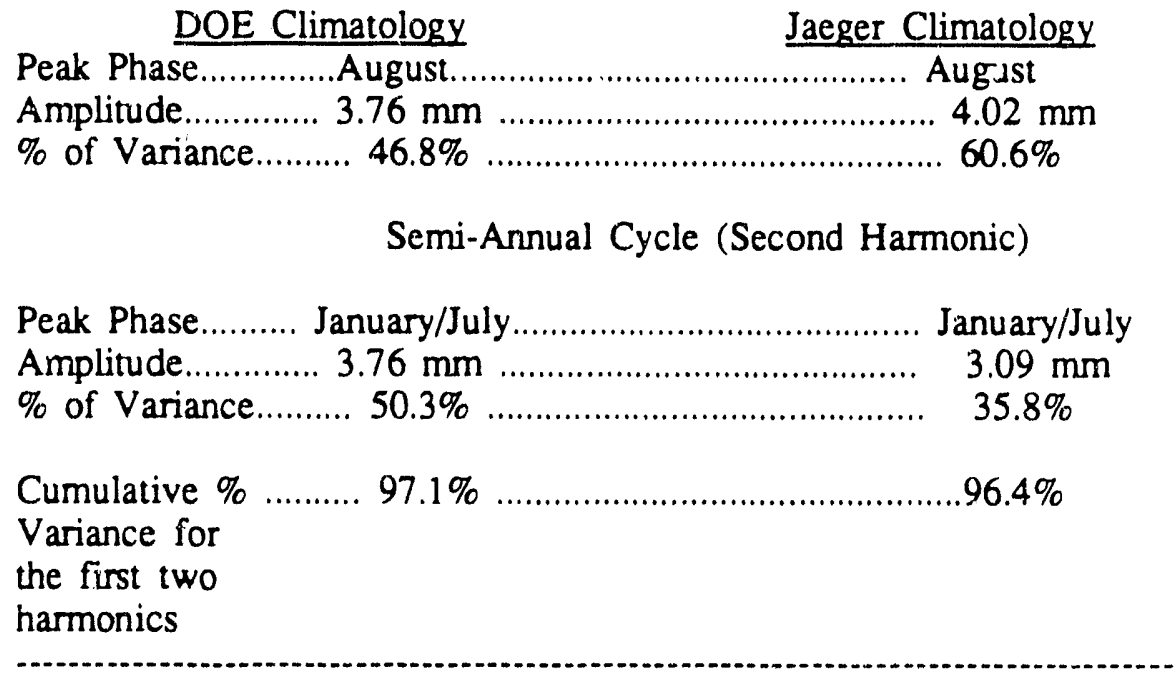




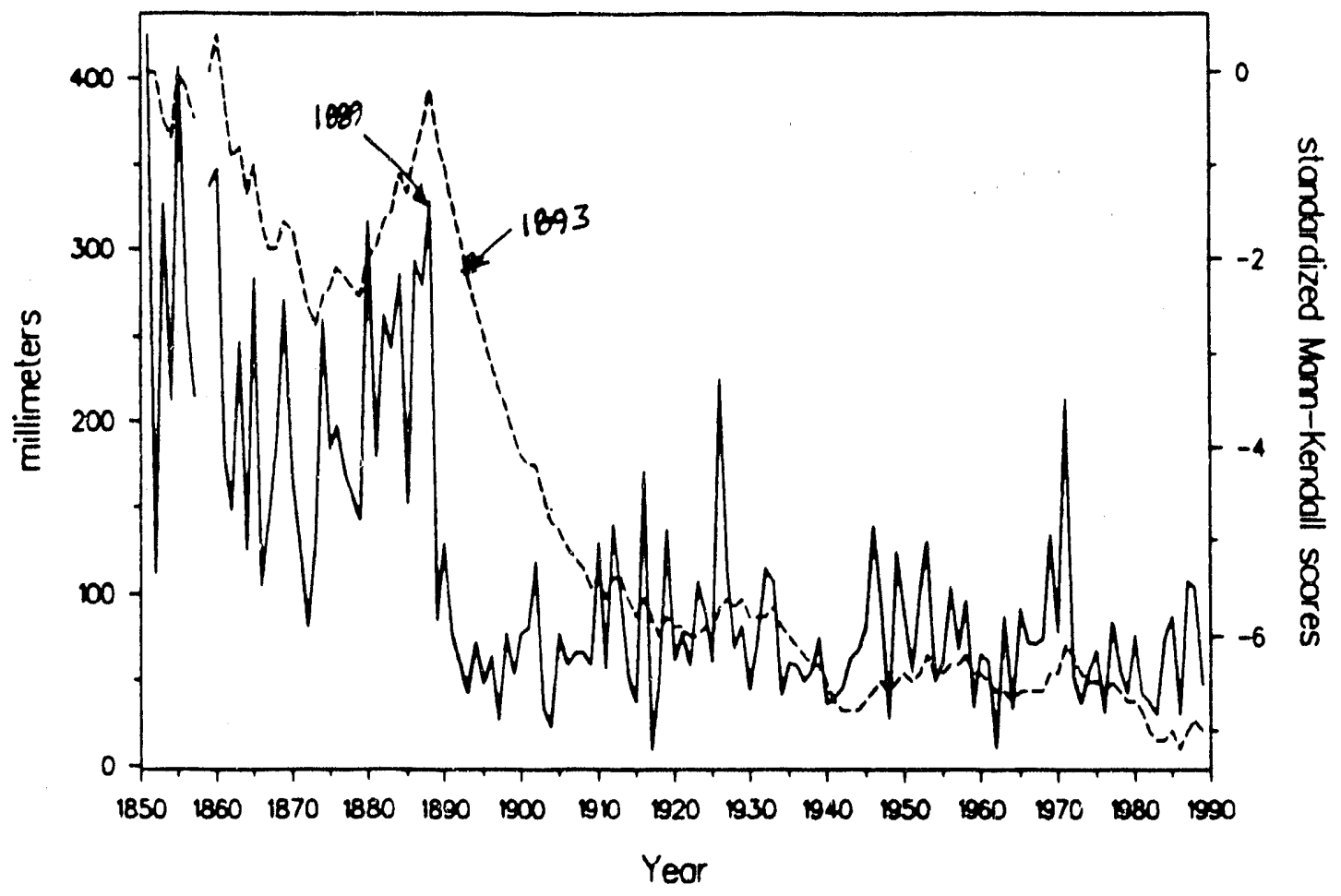

Figure 1. Mean June precipitation and values of the sequential Marn-kendall rank statistic

precipitation in millimeters - Maun-Kendall rank statistic 


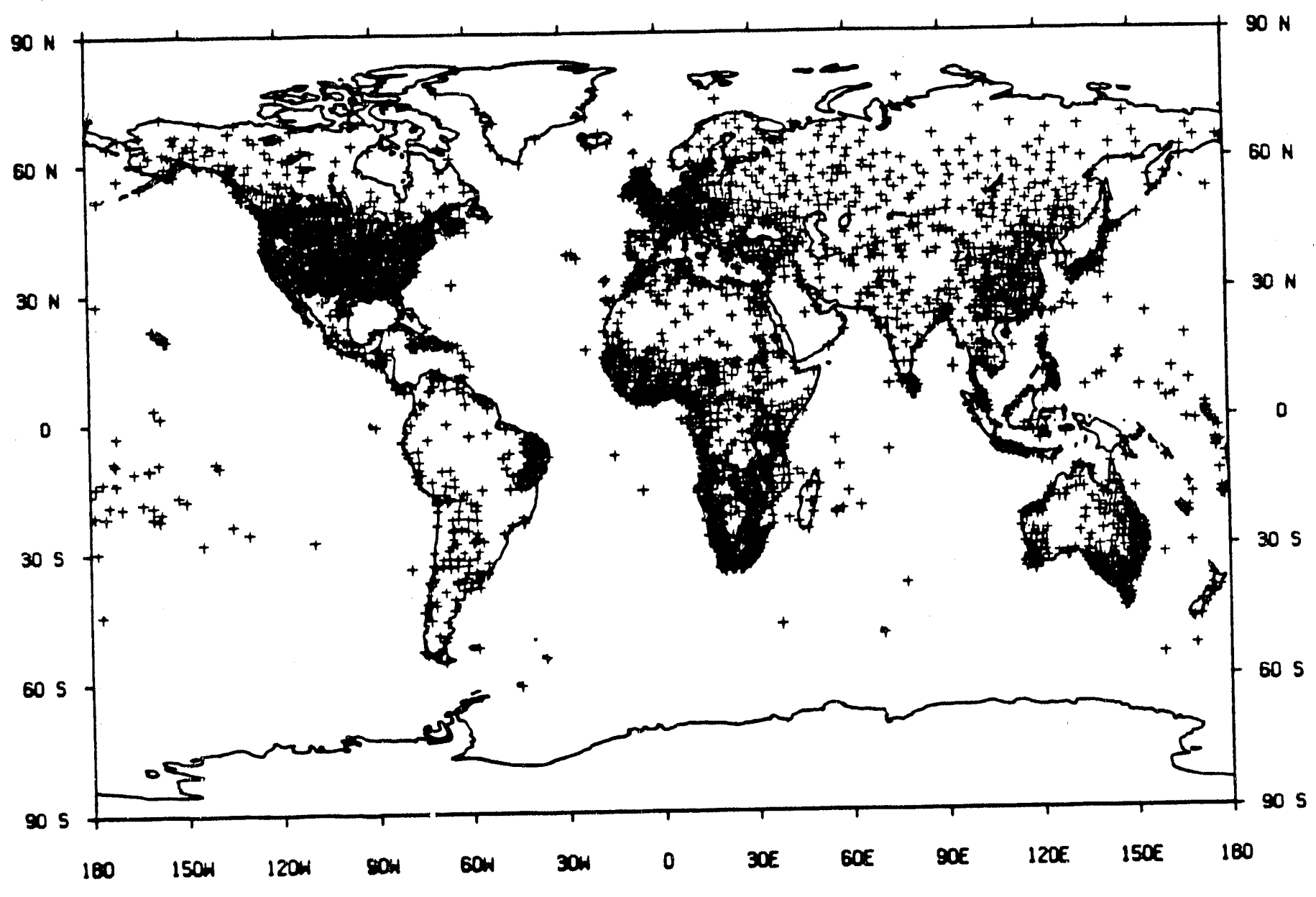

Figure Za Station locations of the 4821 stations in the data Set. 


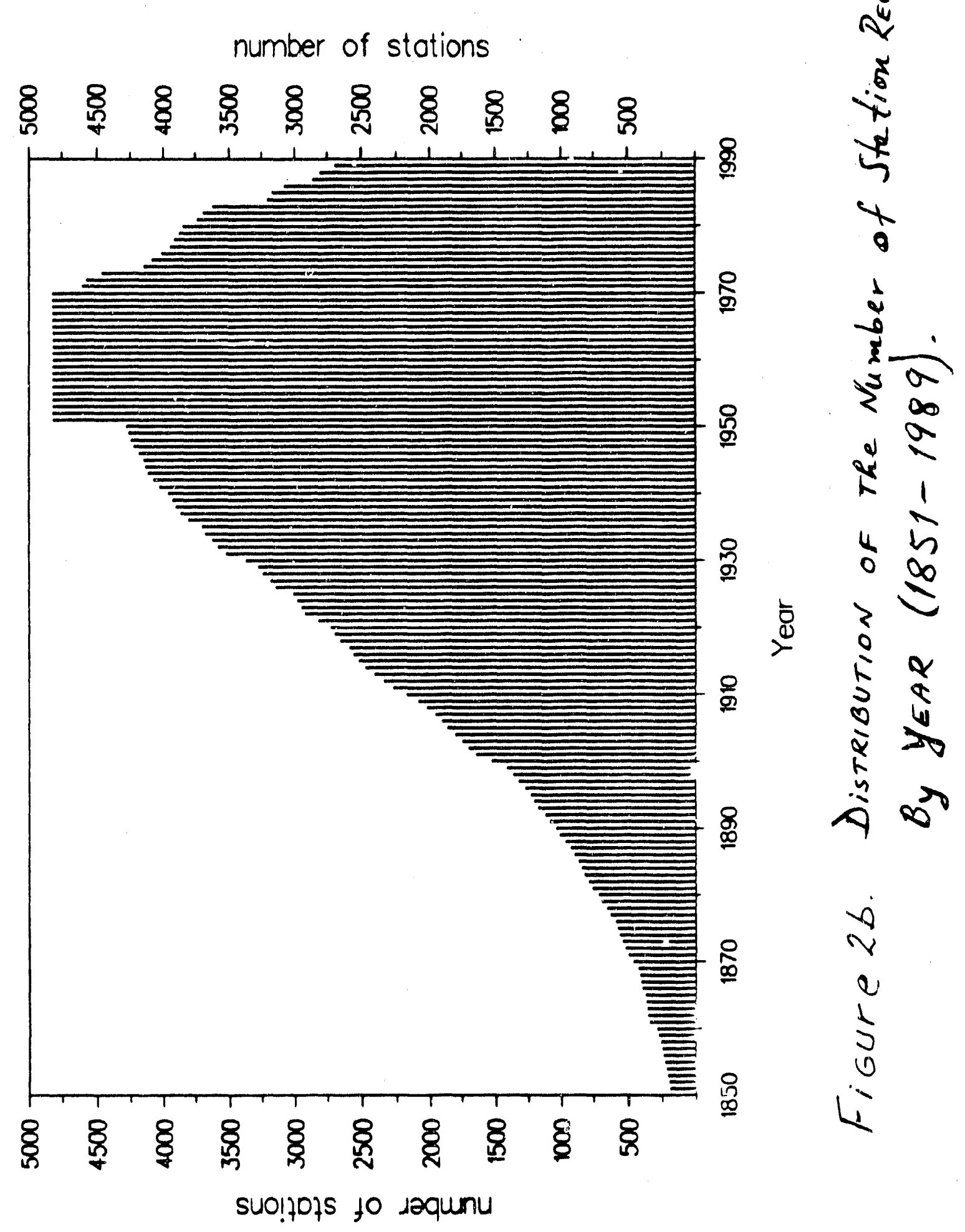




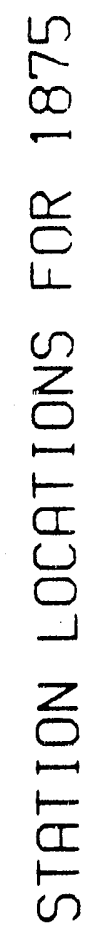

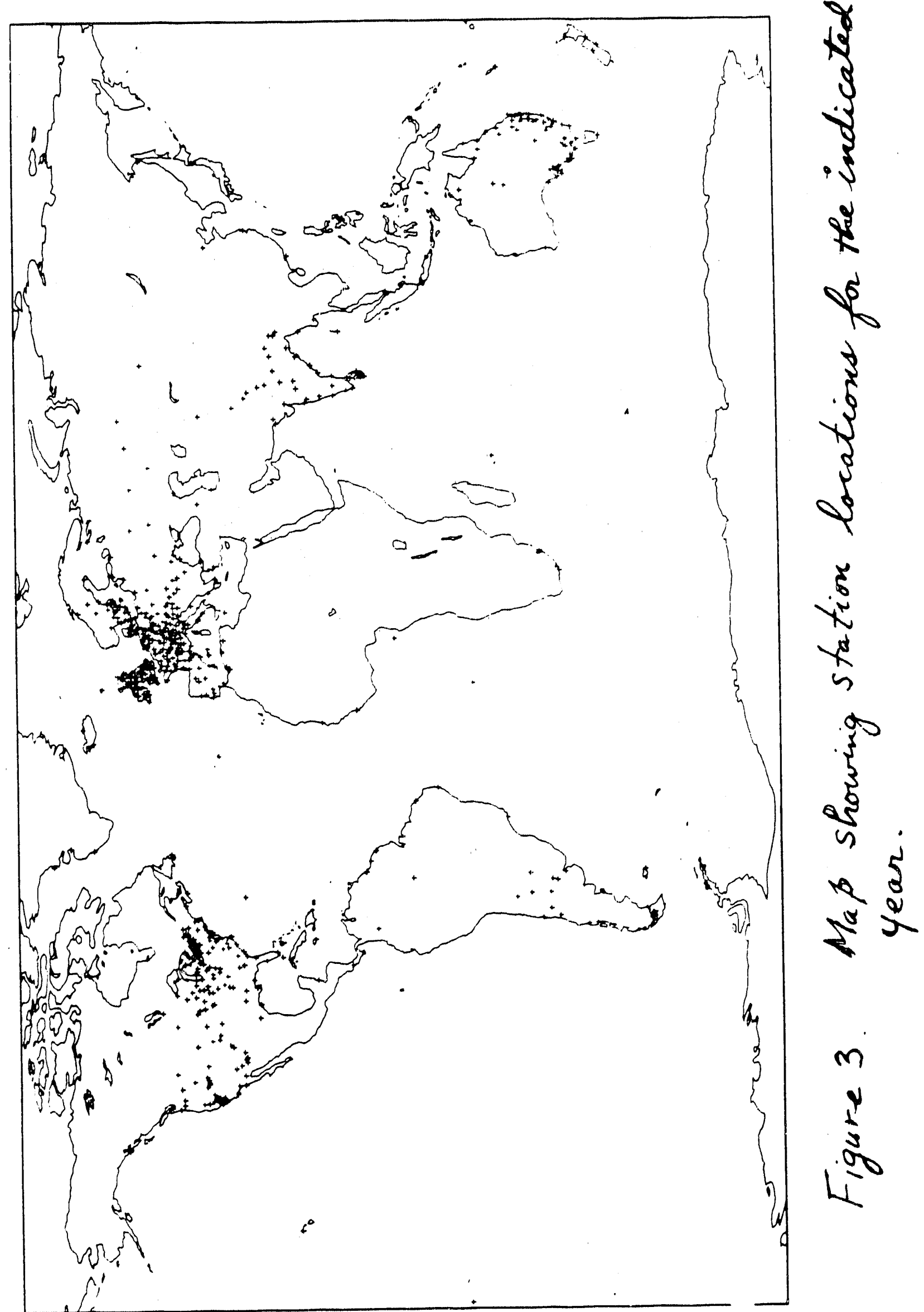




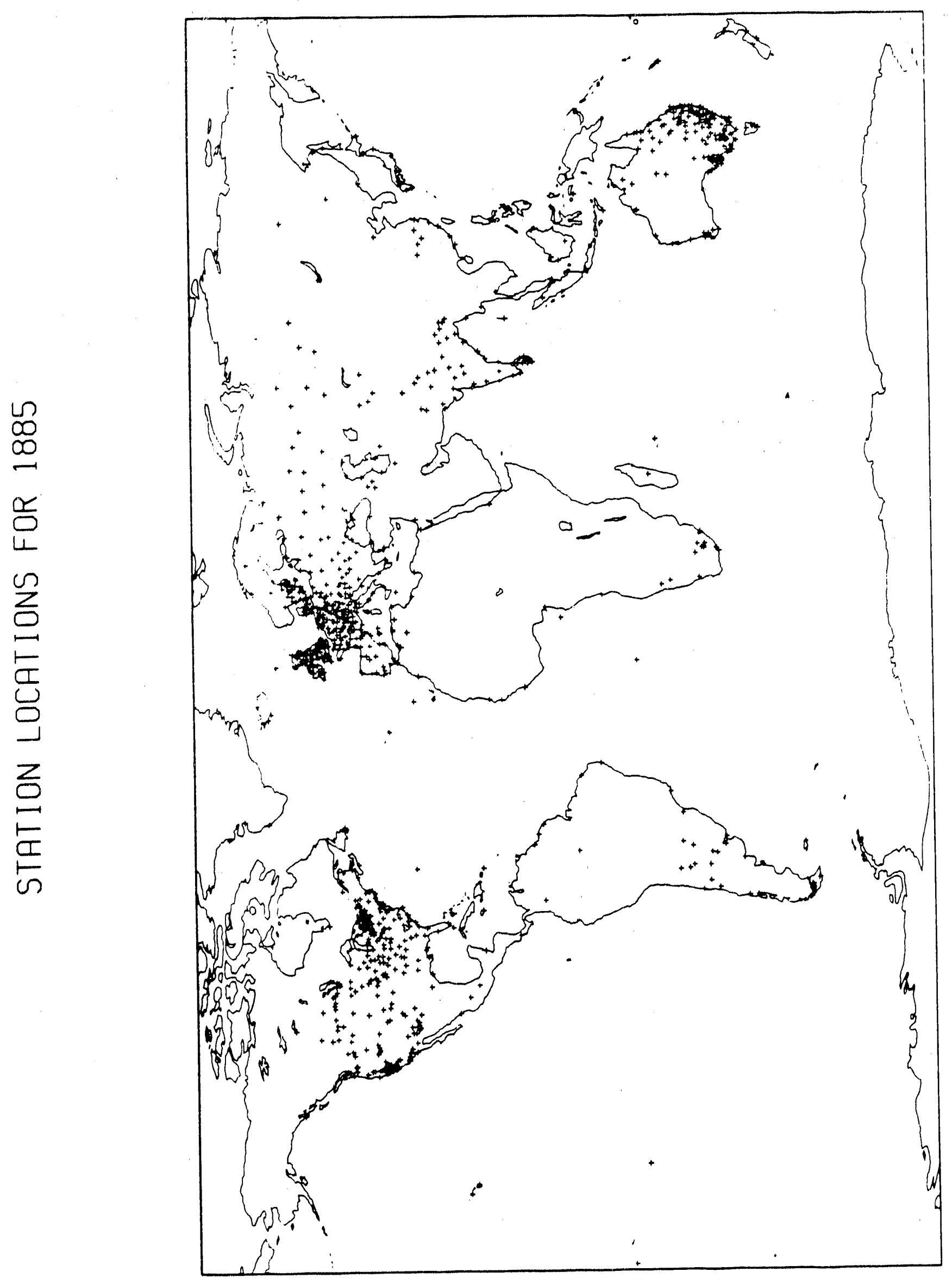




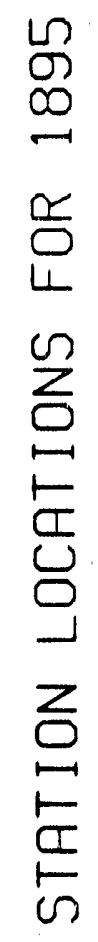

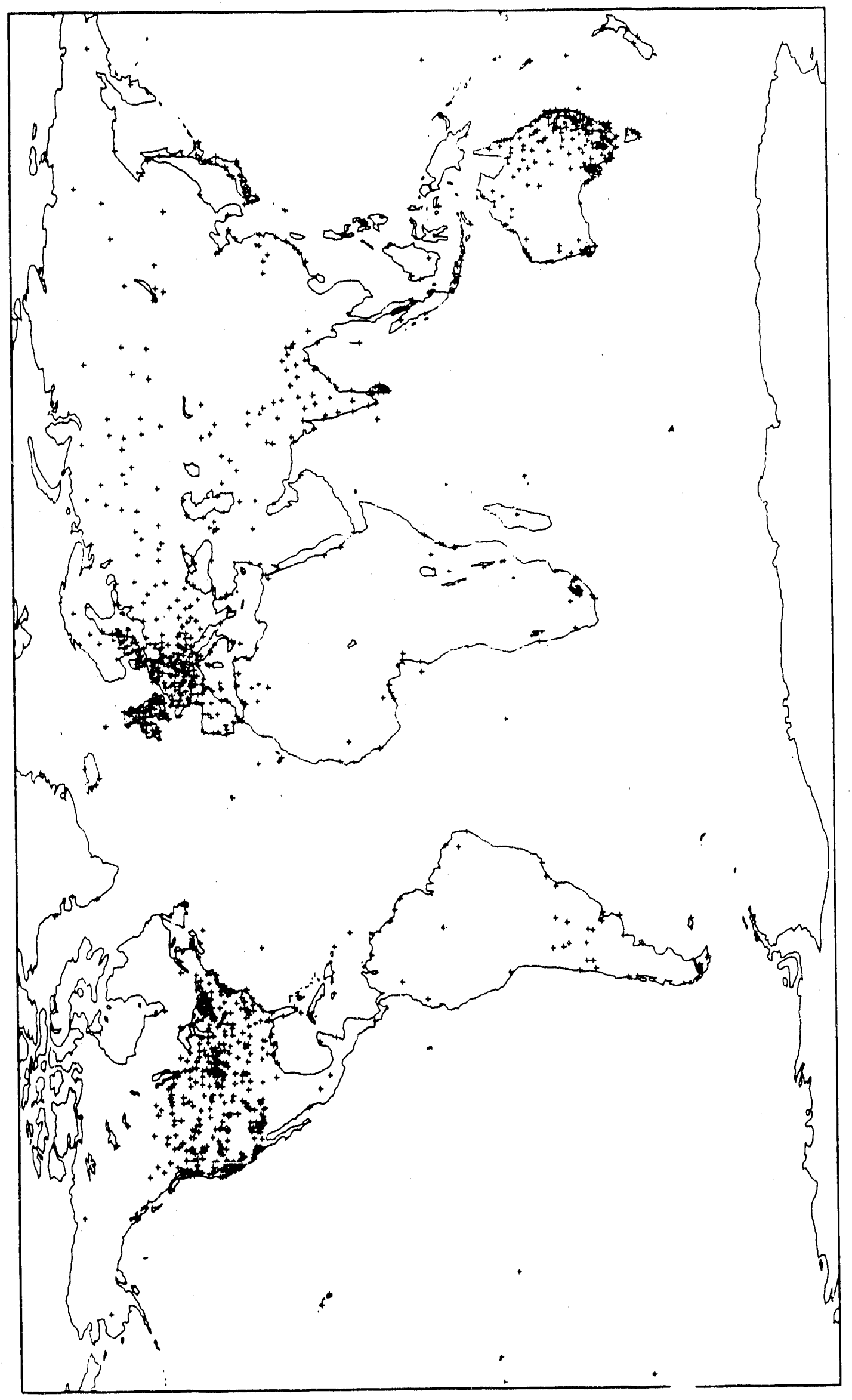




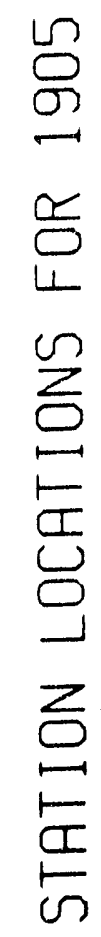

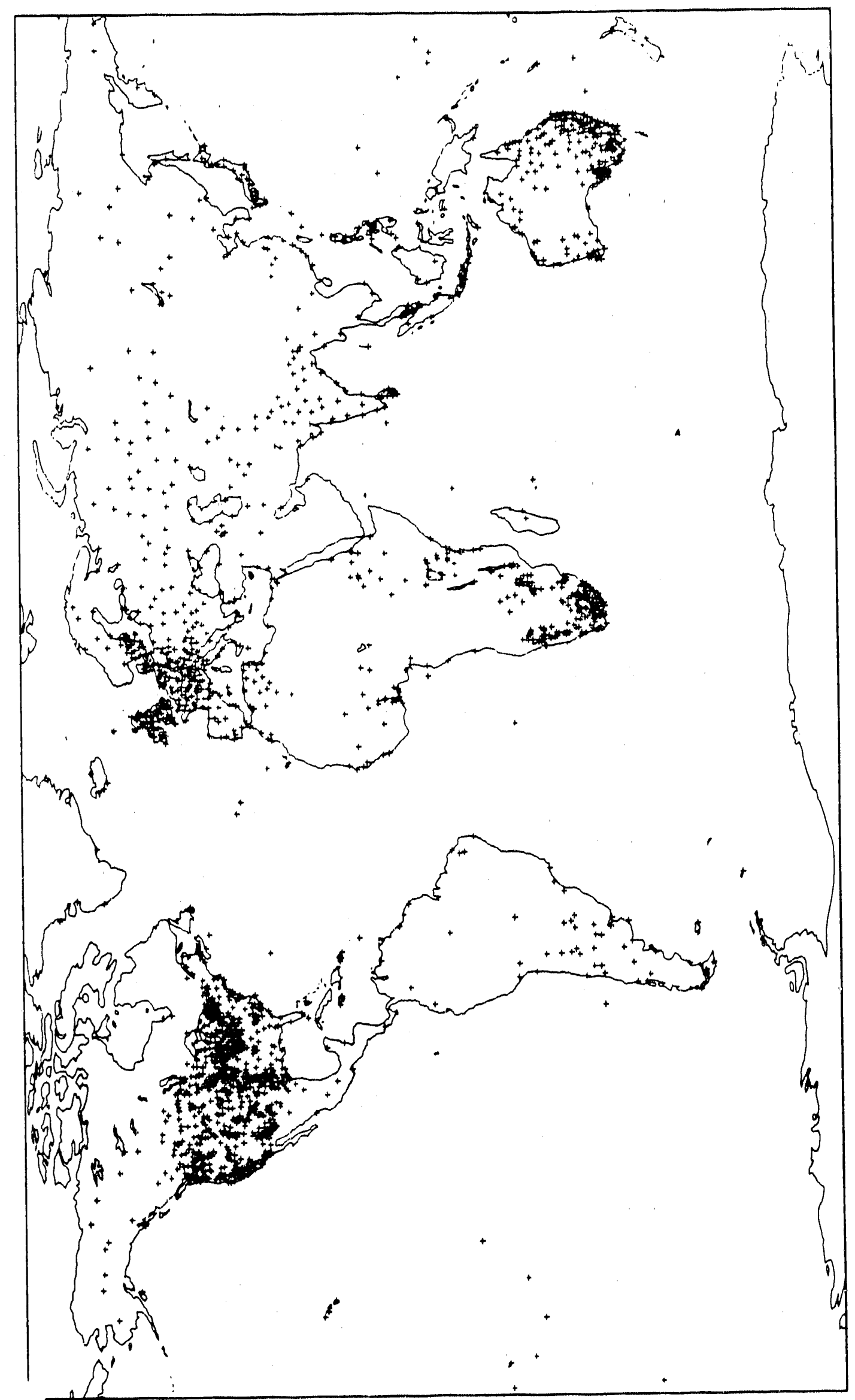




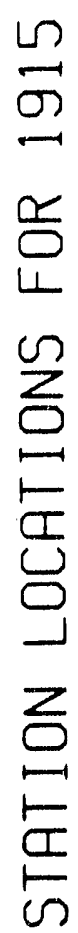

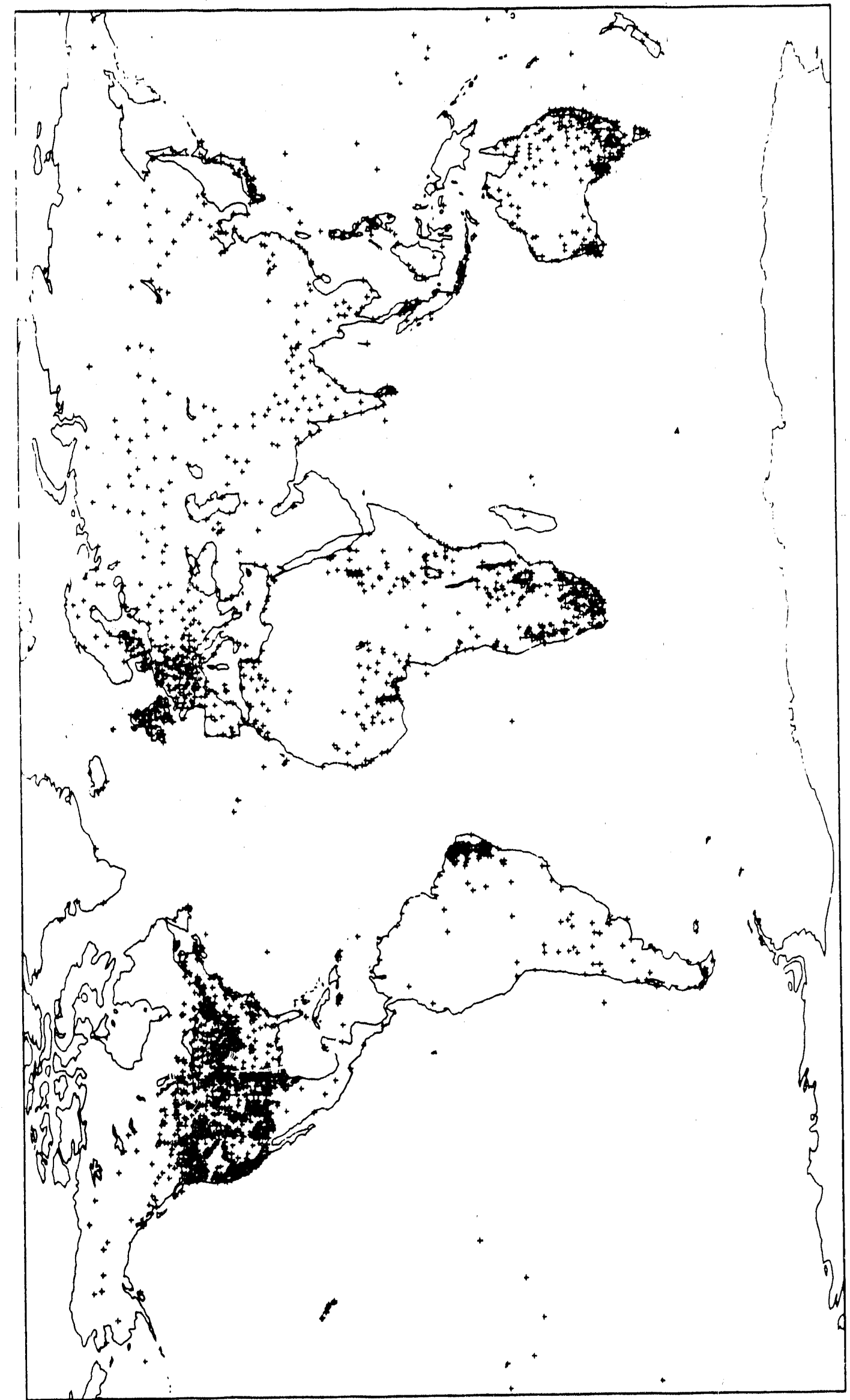




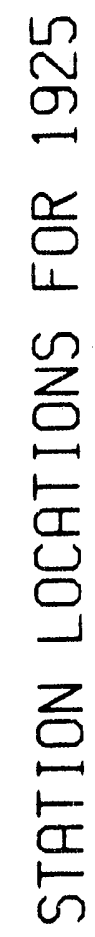

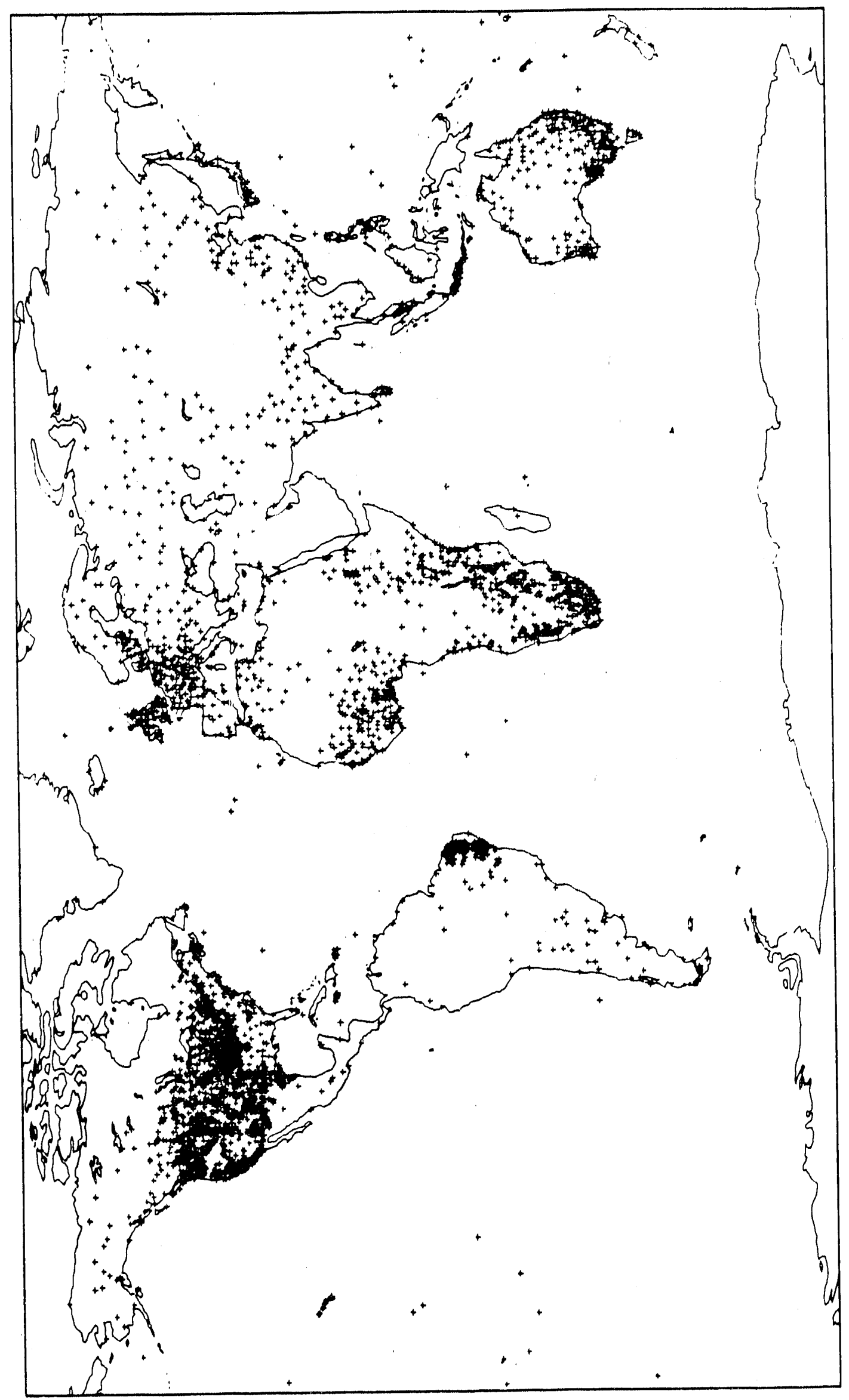



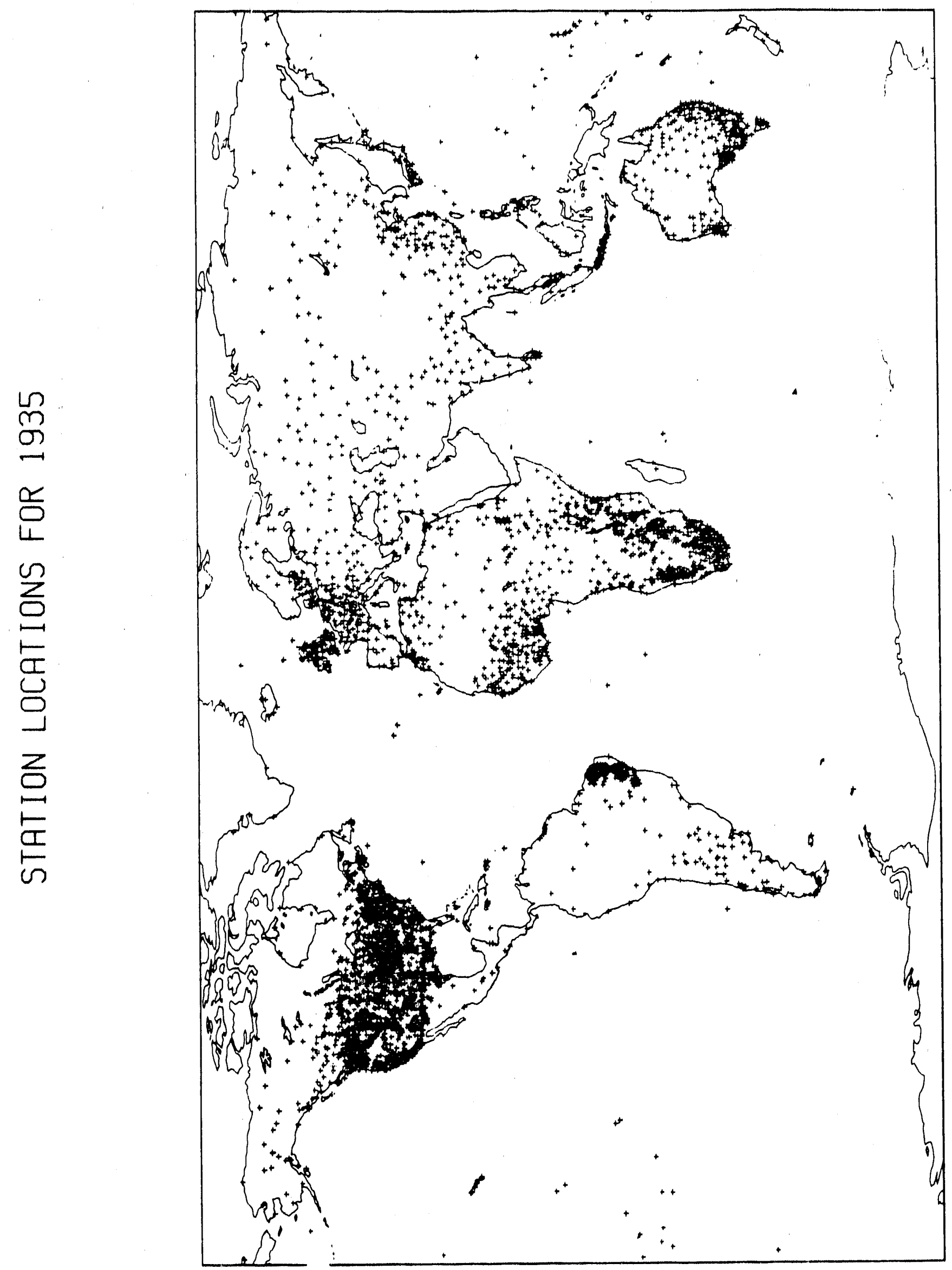


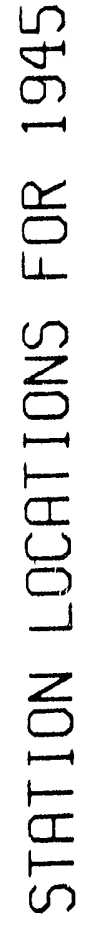

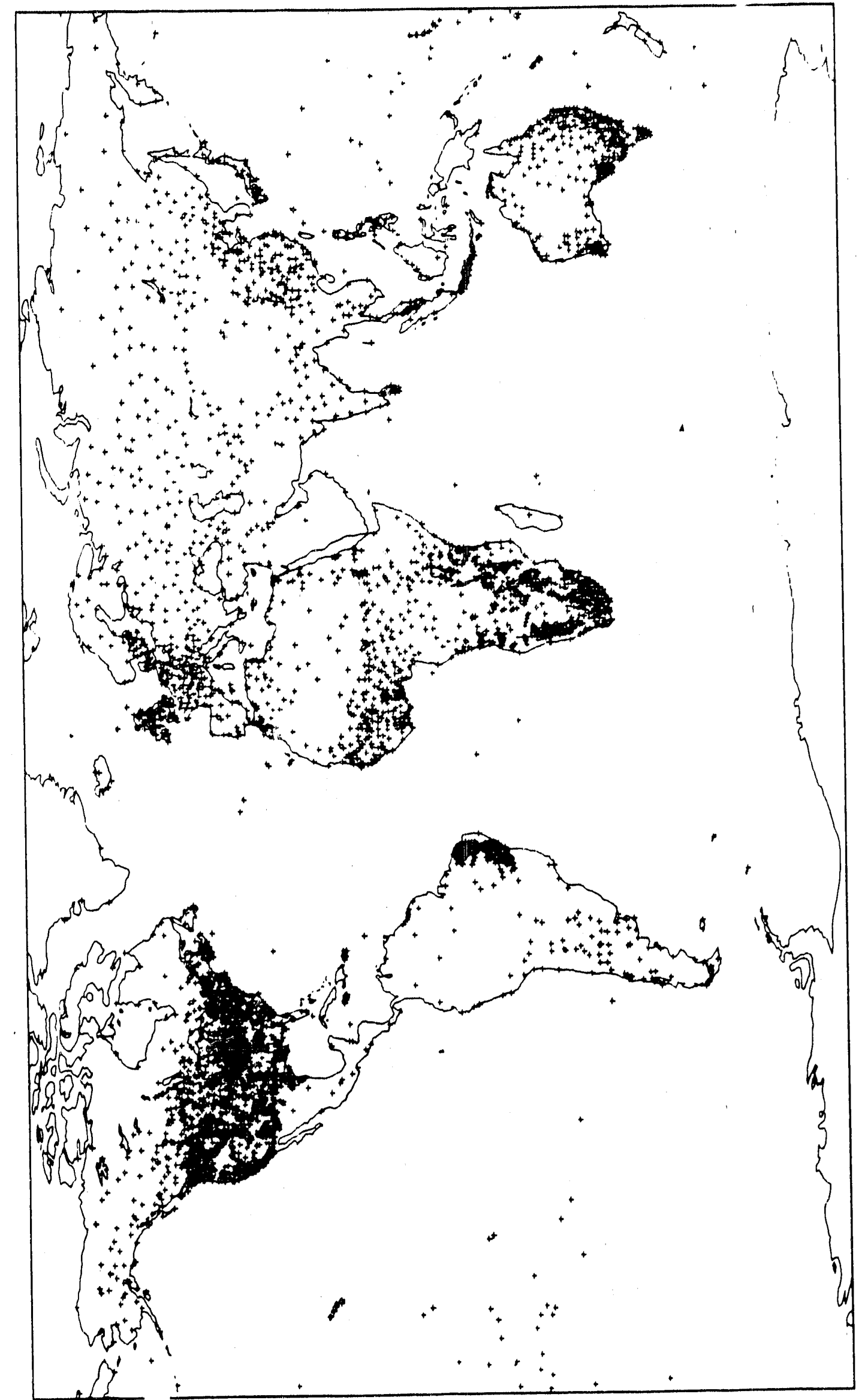




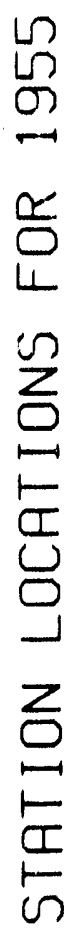

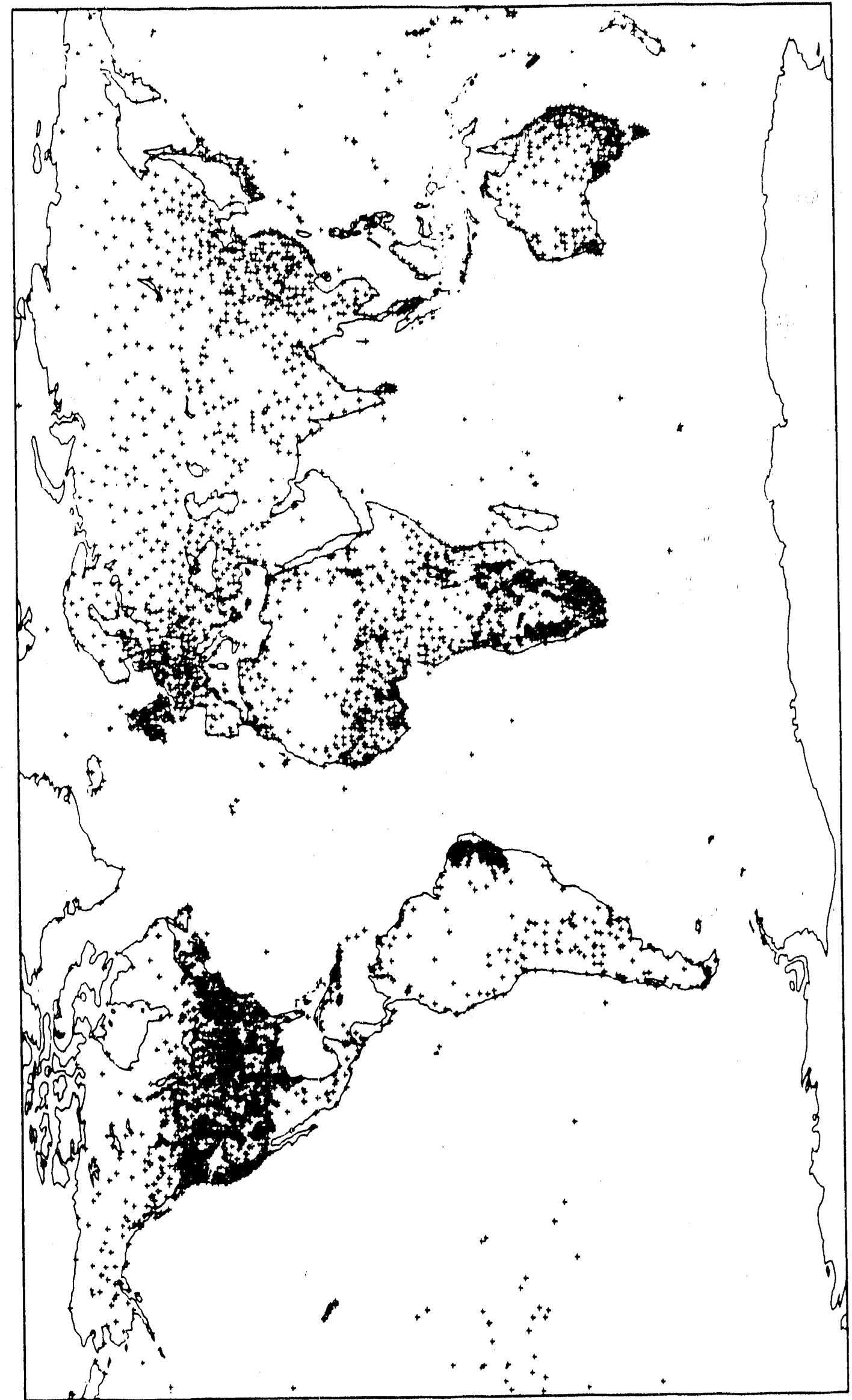




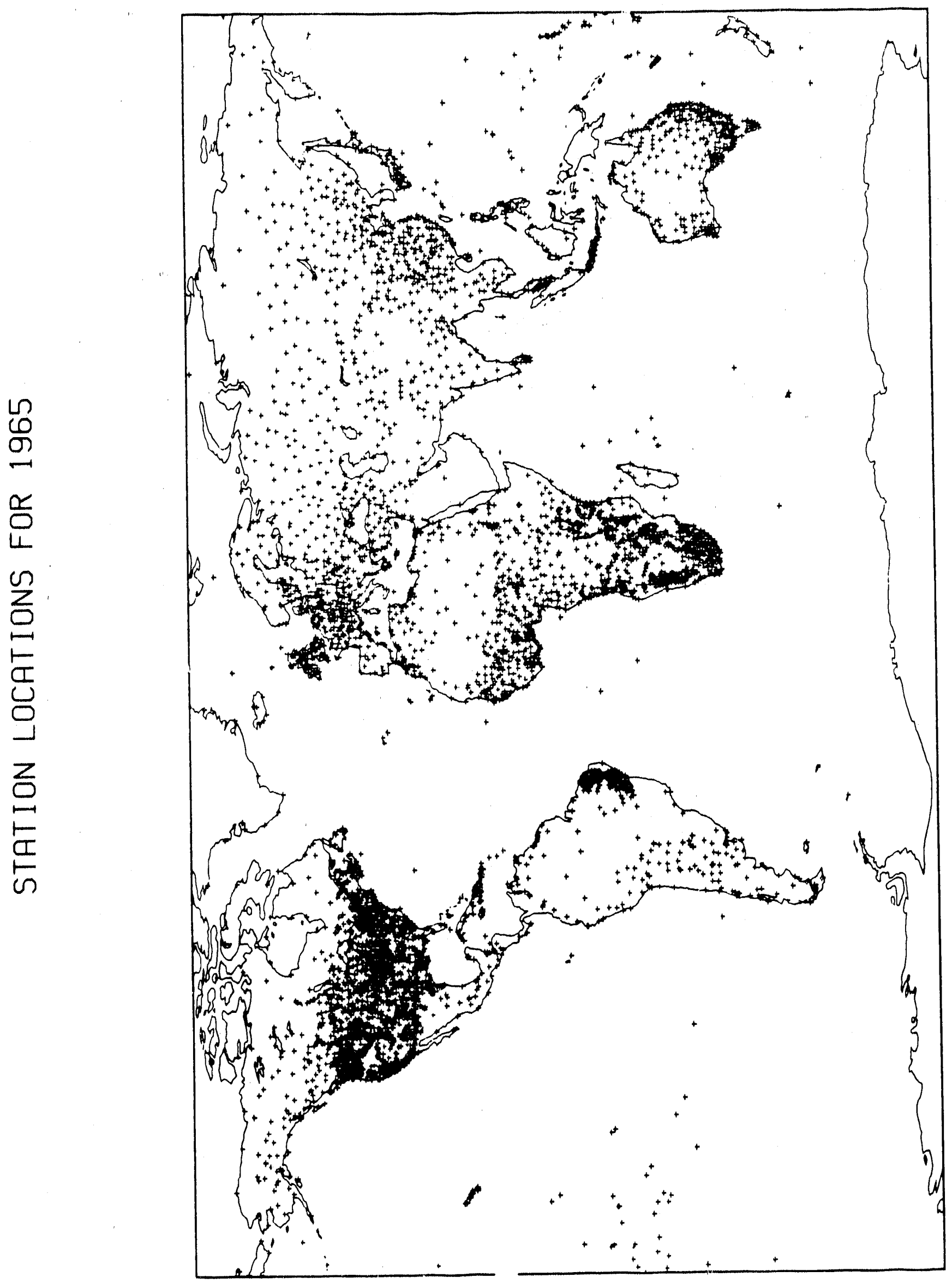




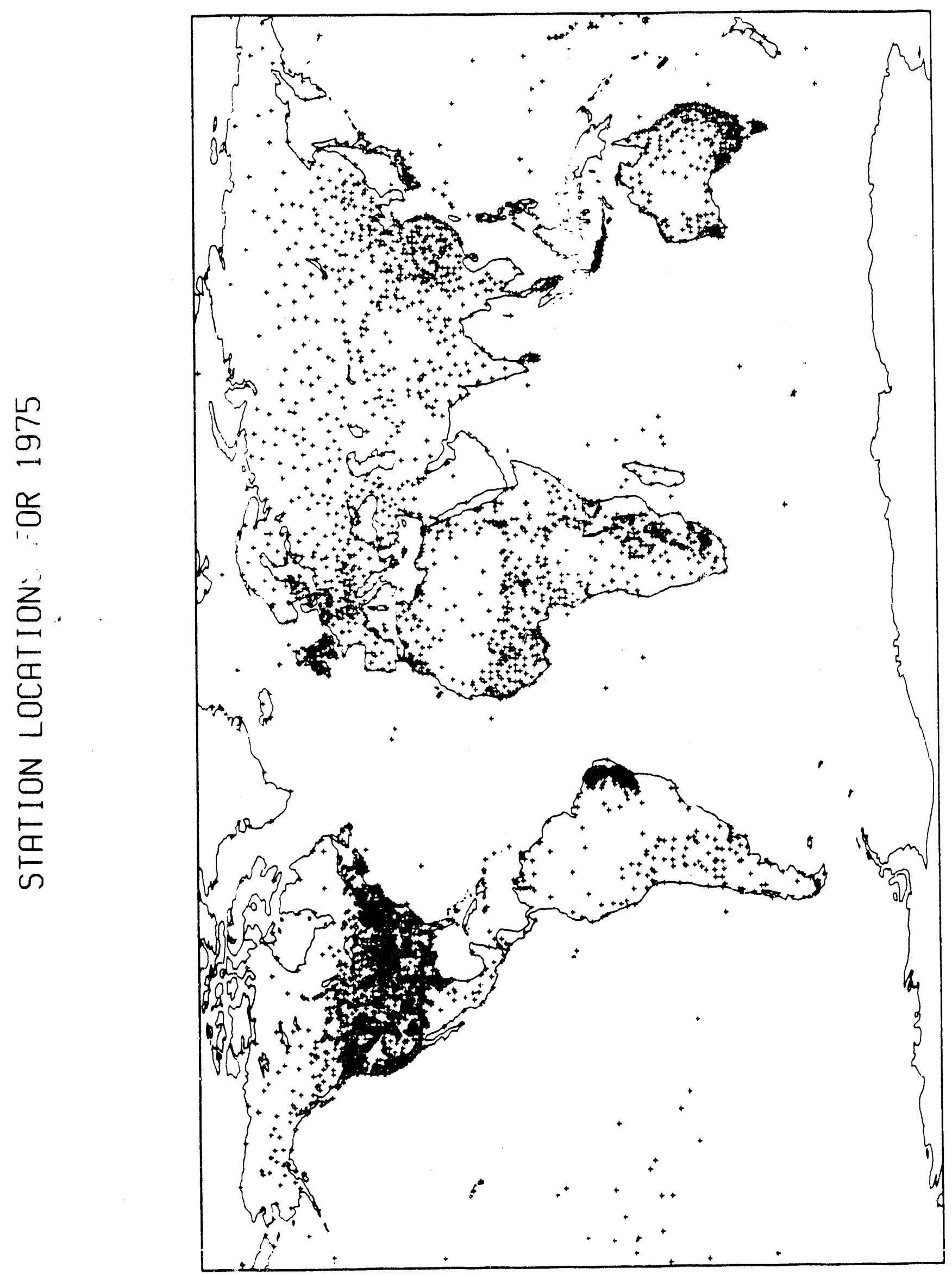




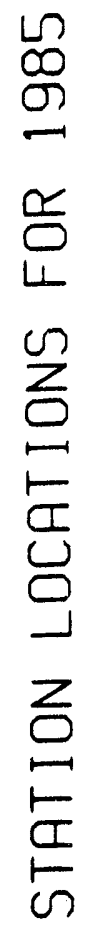

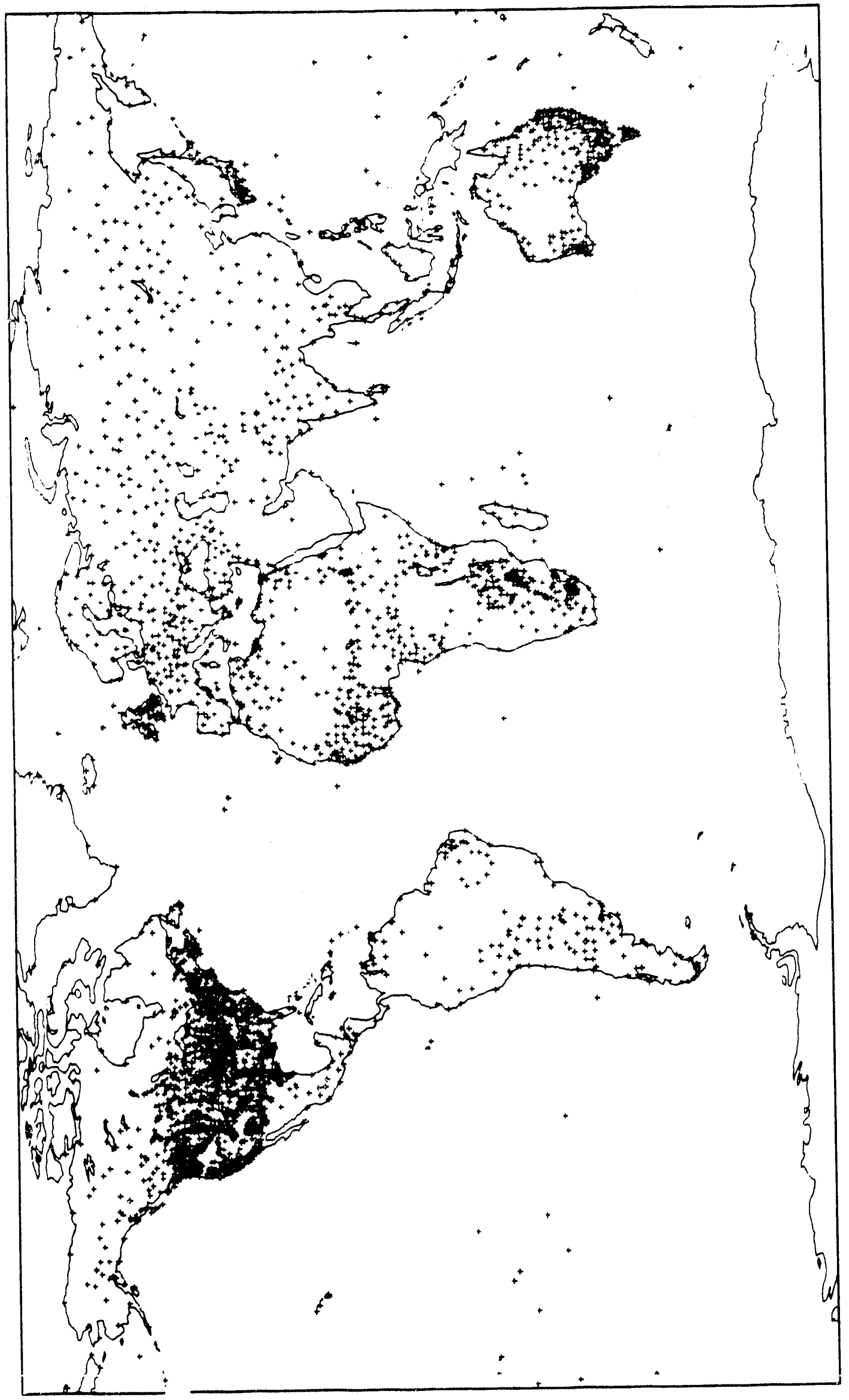




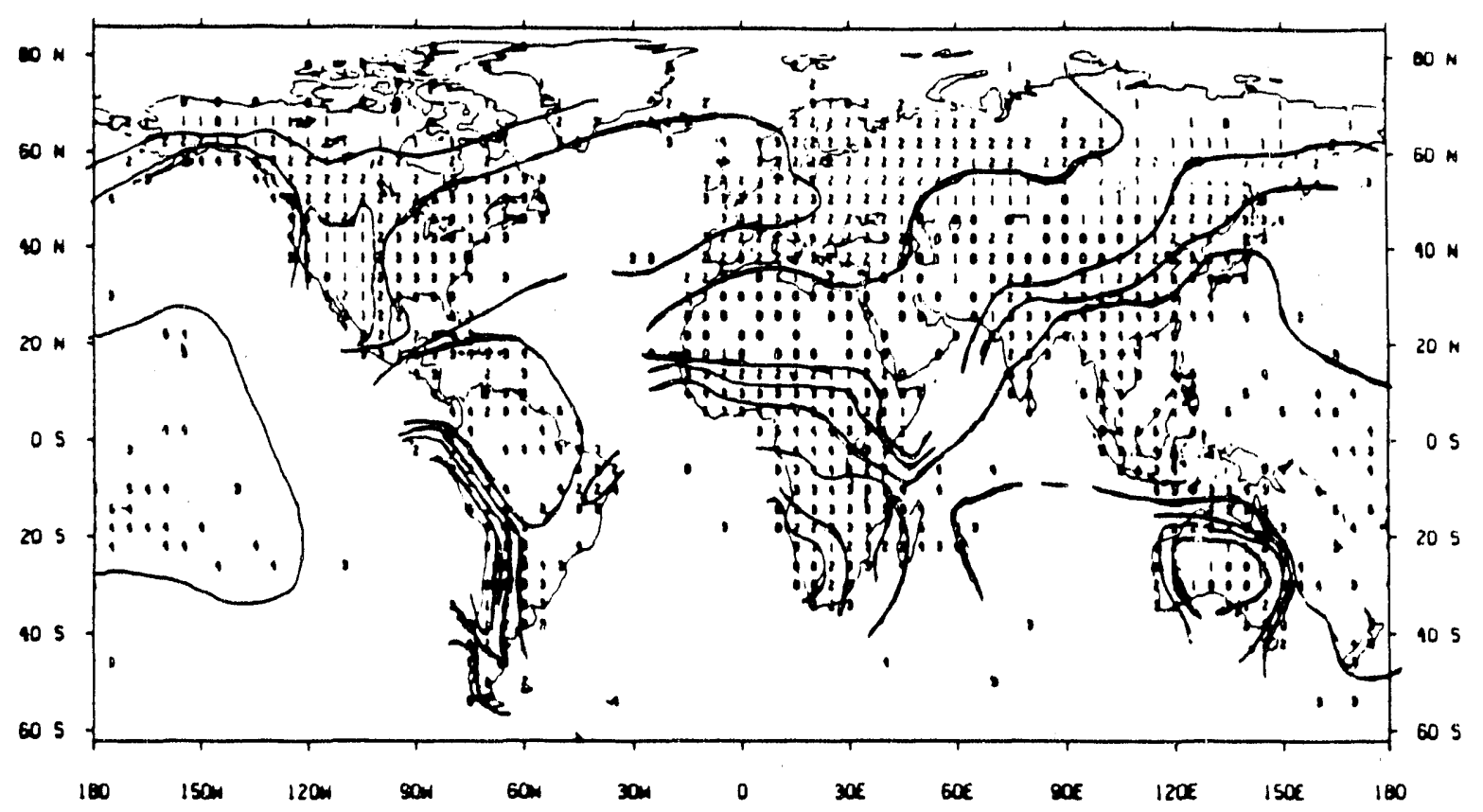

Fig. 4 a Mean Annual Precipitation for doe Climatology. Integer Values Correspond to the intervals: $0<182.5$ $t=182.5-3 i 5, Z=365-730,3=730-1460,4=1460-2720,5=2920-4380$, $6>4380$ anear -1

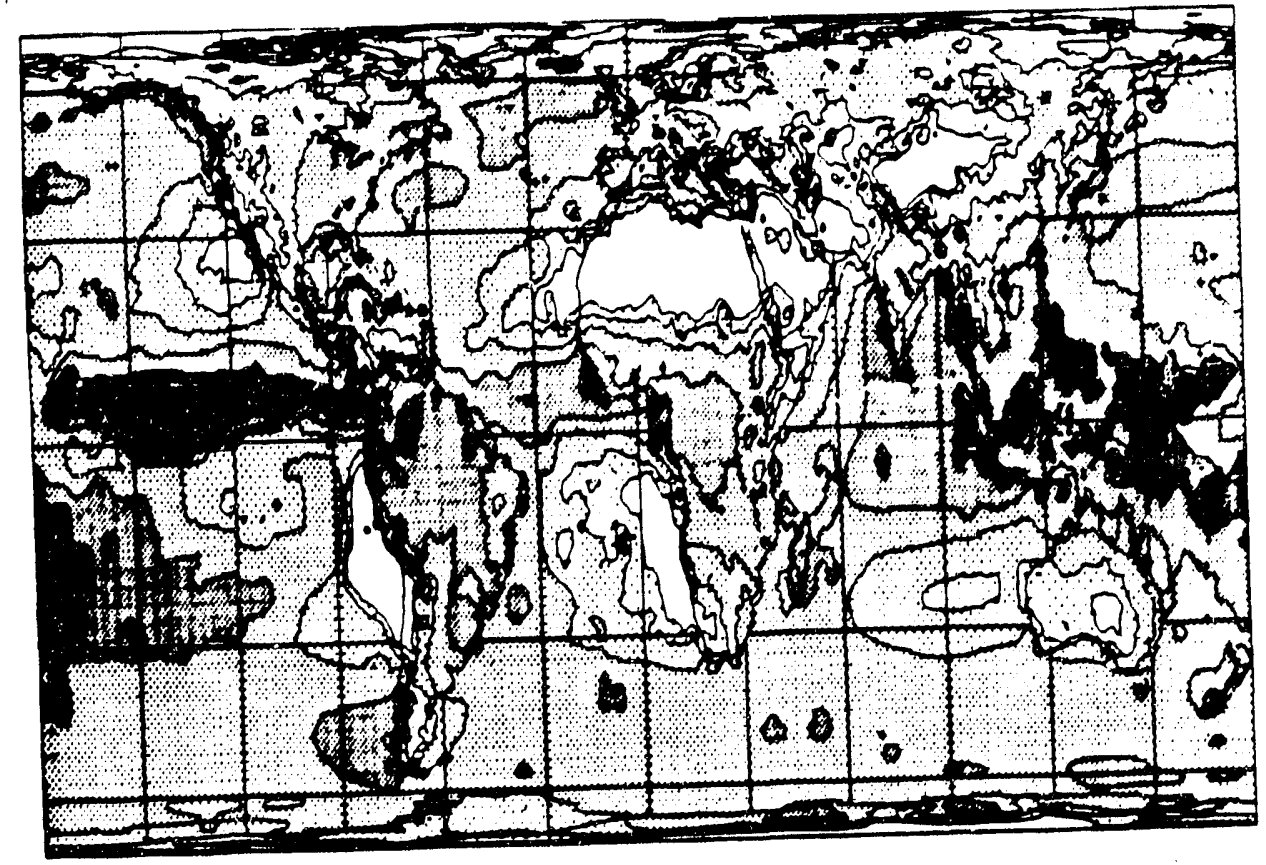

Fig. $4 b$ mean annual precipitation the the LW dimatology. Isohyets are B22.5, 365, 730, 1460, 2920 and $4380 \mathrm{~mm}$ your -1. Areas less than 182.5 are unshaded while areas receiving mure than $4380 \mathrm{~mm}_{\text {year }}-1$ are completely blackened. Figure taken for Legates and will mott (1989). 


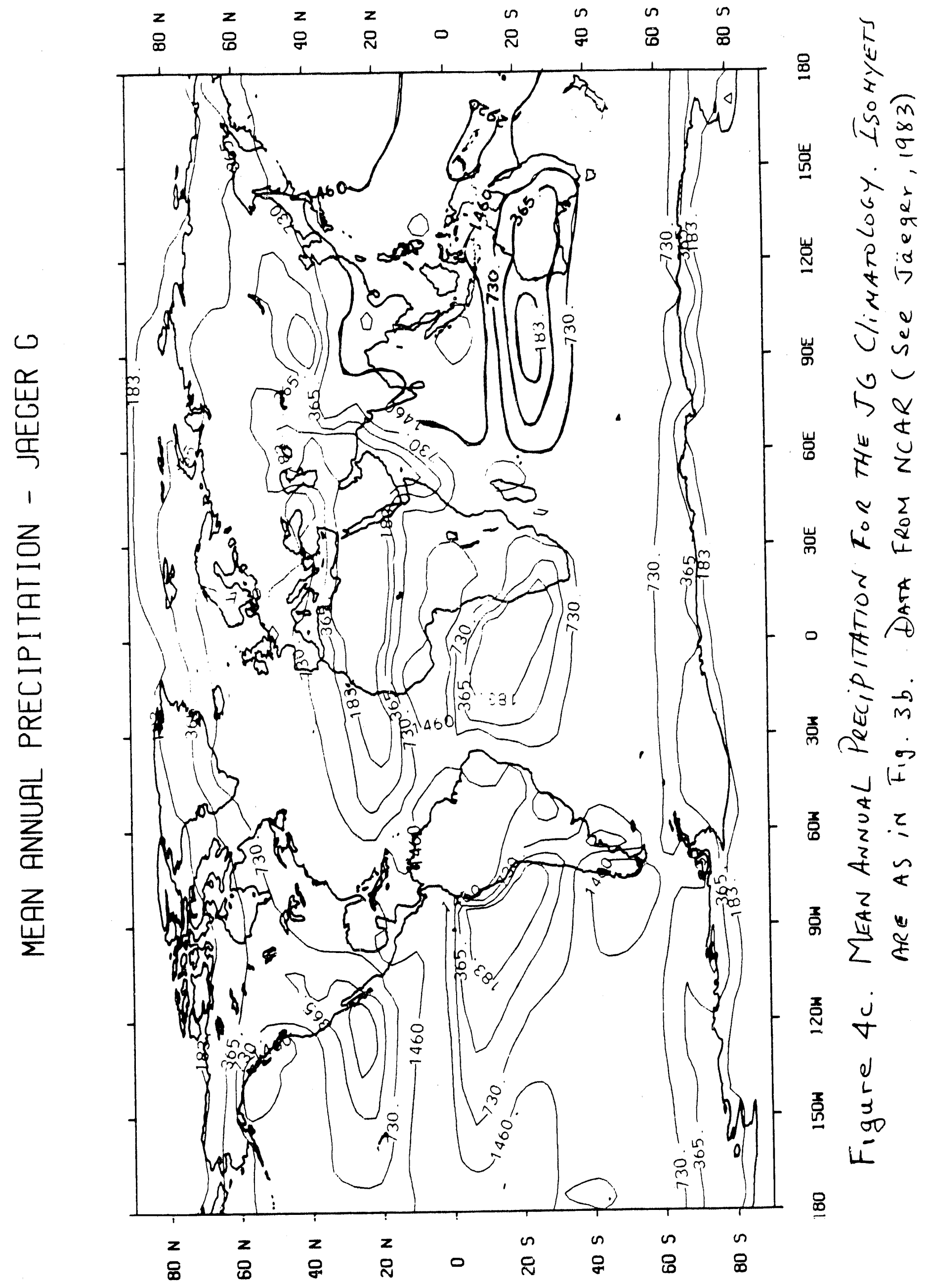



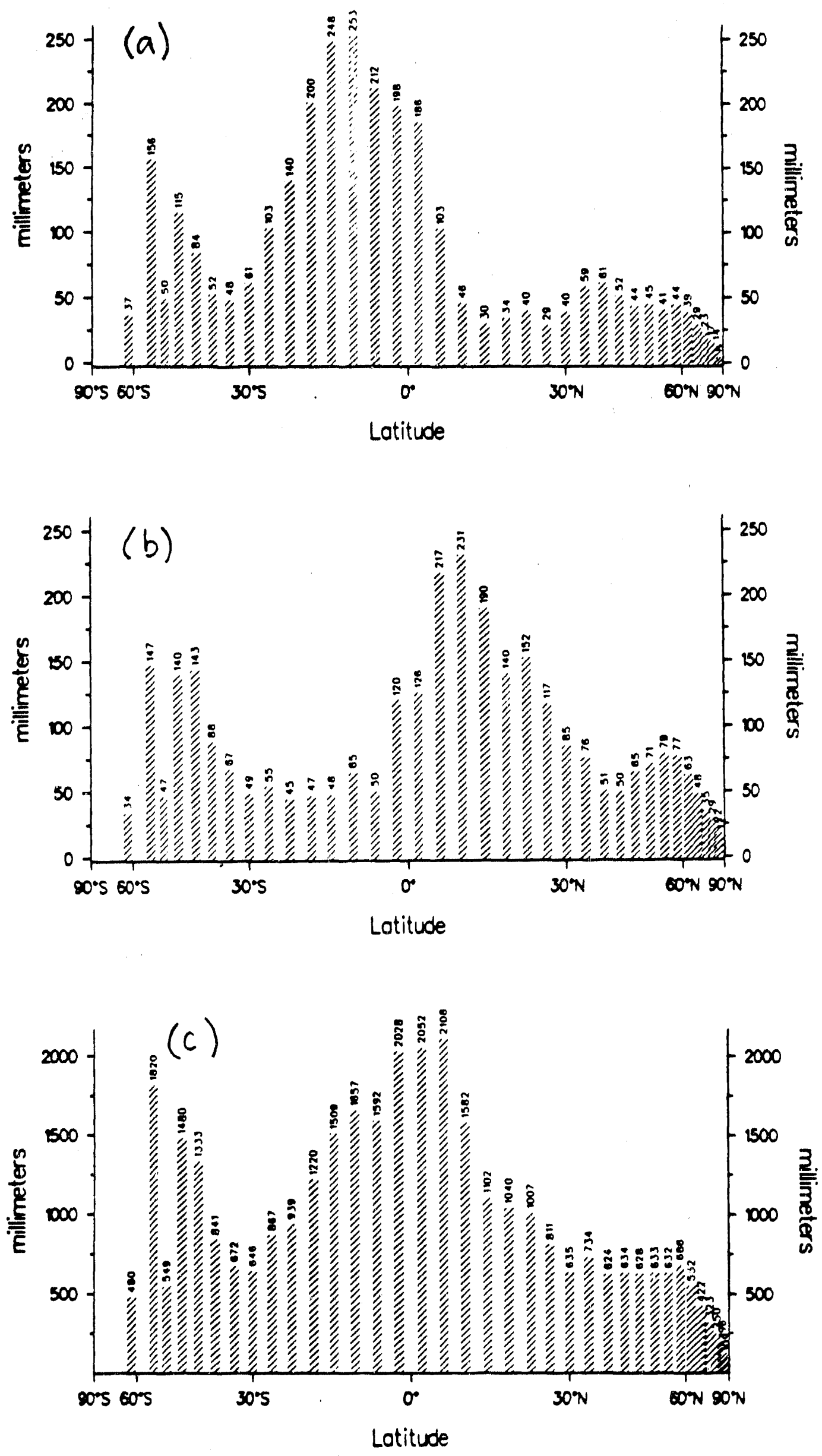

Figure 5. Variation of mean precipitation with latitude for the DOE grid: (a) January; (b) July; (c) aunual. 

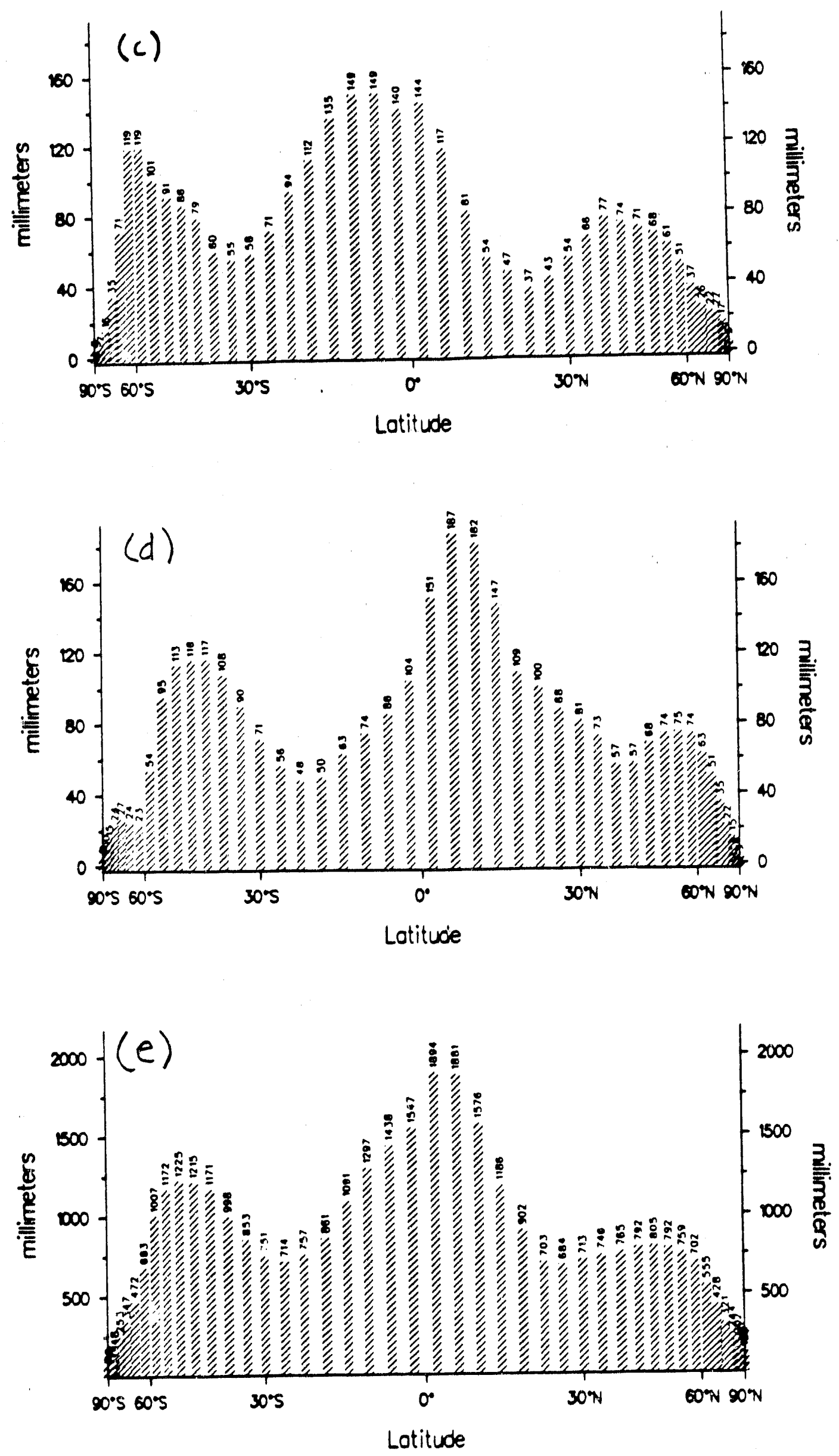

Figure 5. Variation of mean precipitation with latitude for the JG grid! (c) January; (d) July; (e) annual. 
(a) DOE

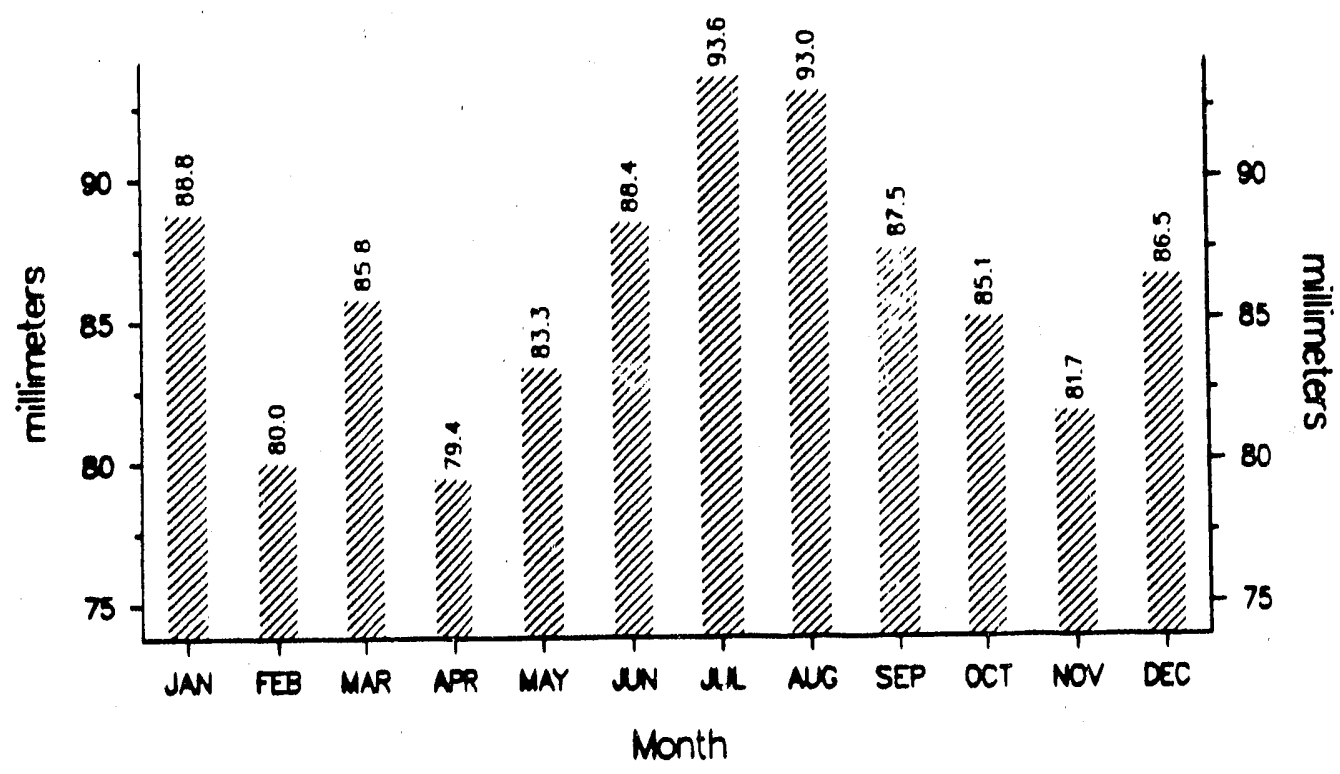

(b) Jäeger

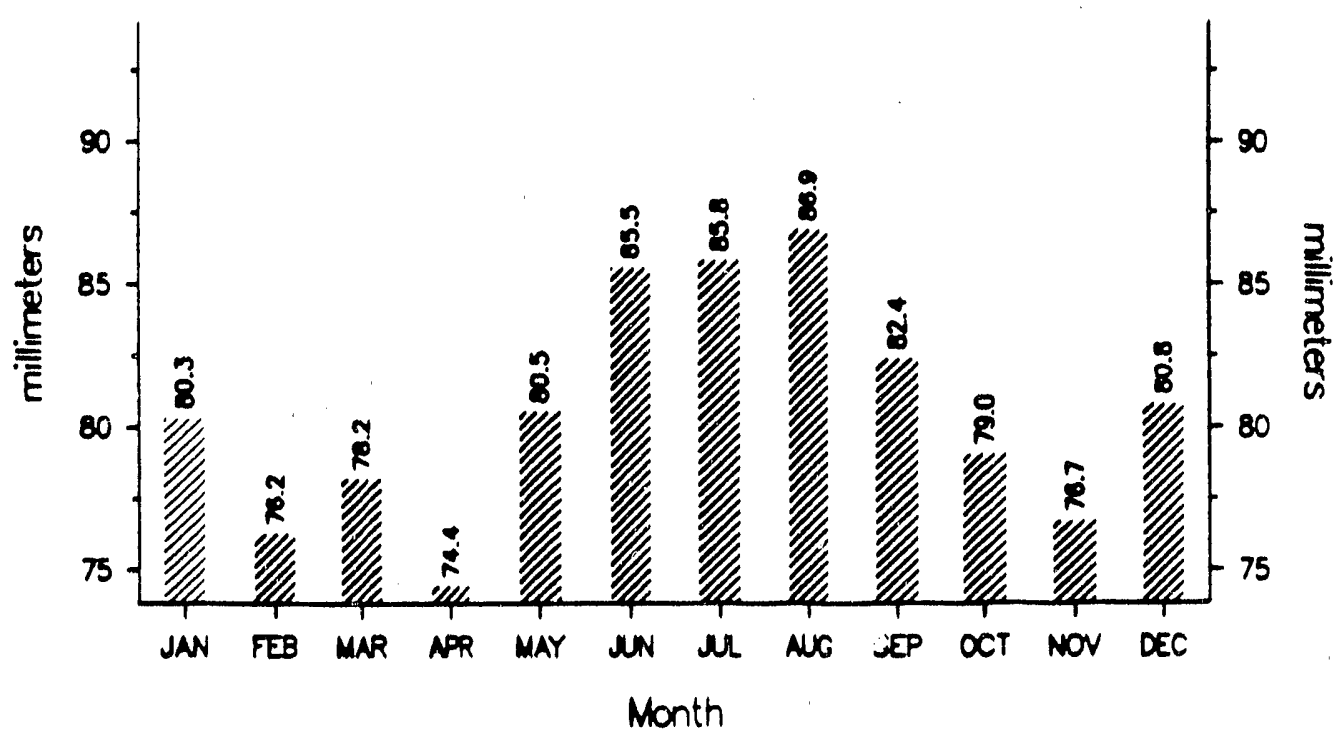

Figure 6. Mean Monthly Precipitation: (a) DOE climatology; (b) JG chimatology 


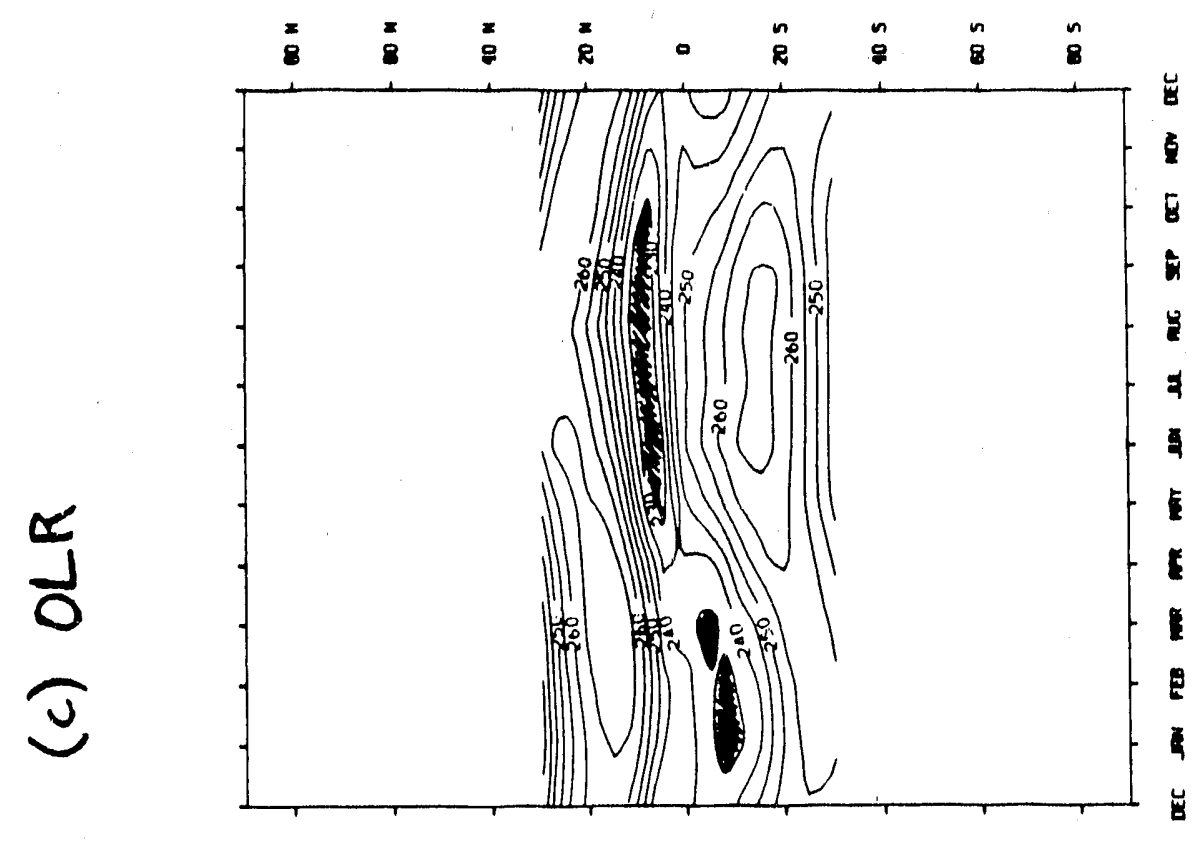

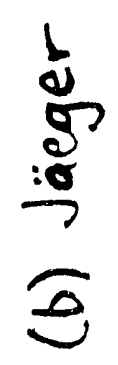
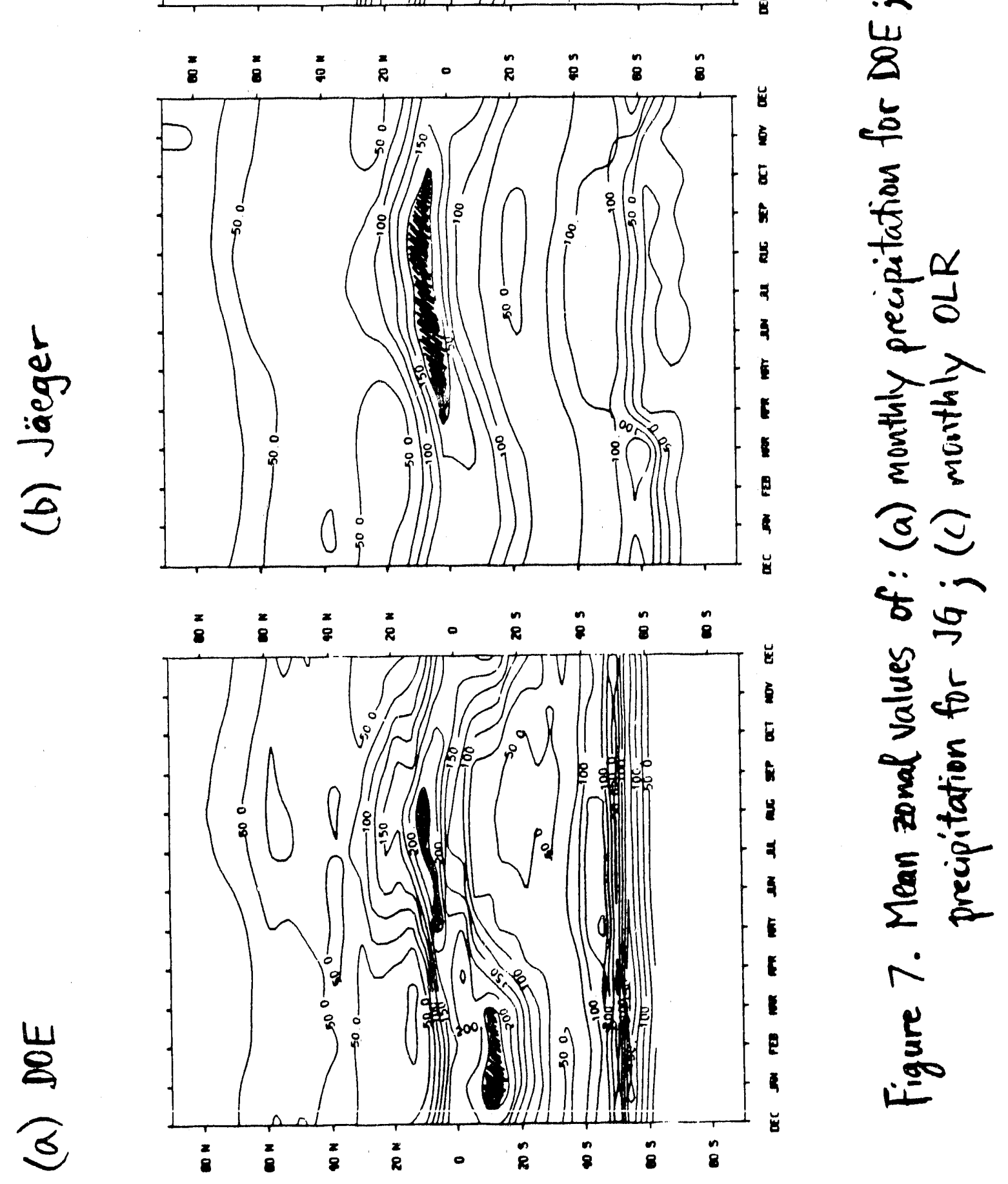


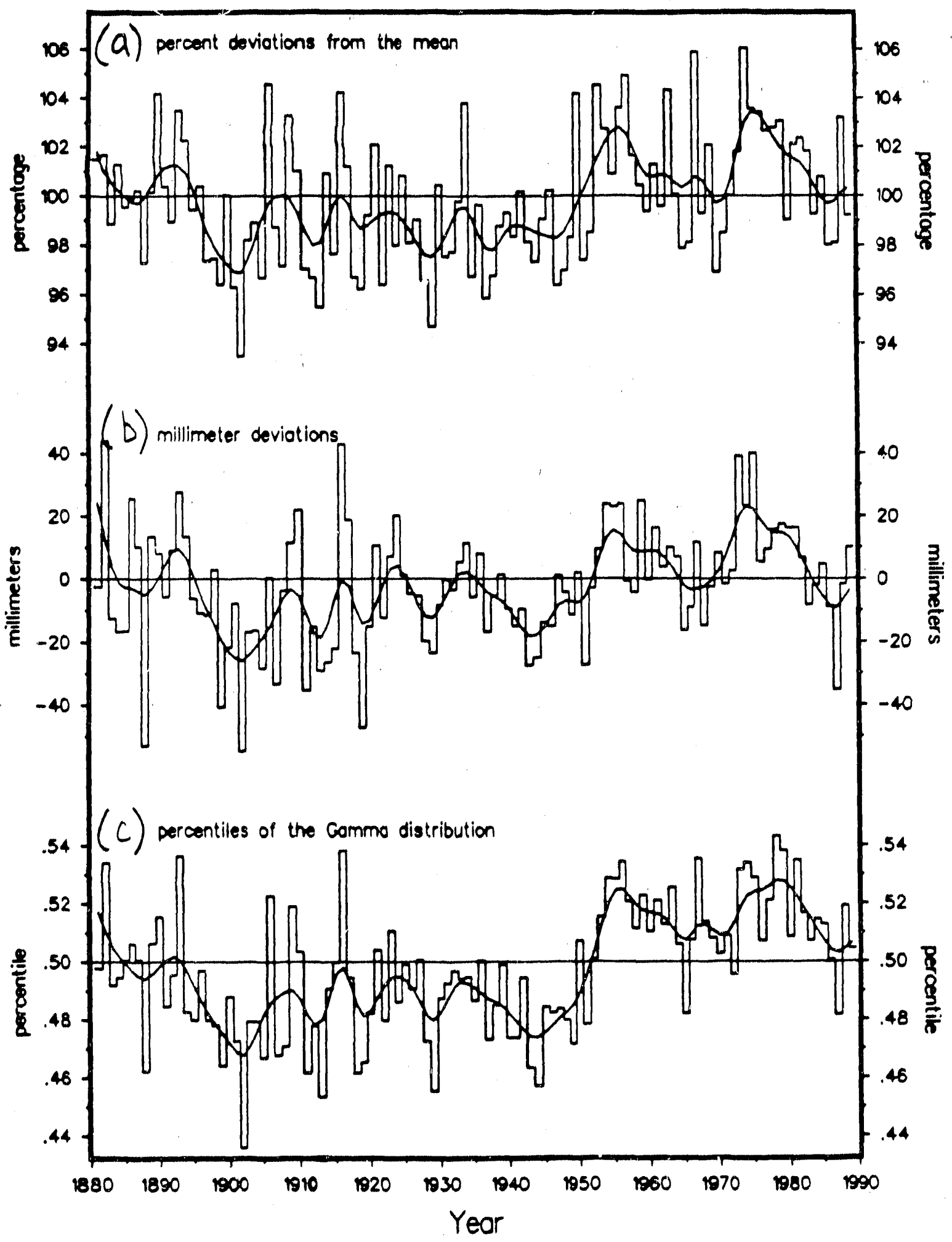

Figure 8. Variations in global annual precipitation indices for: (a) 70 deviations from mean; (b) millimeter deviations; (c) percentiles of the gamma distribution 
(a)
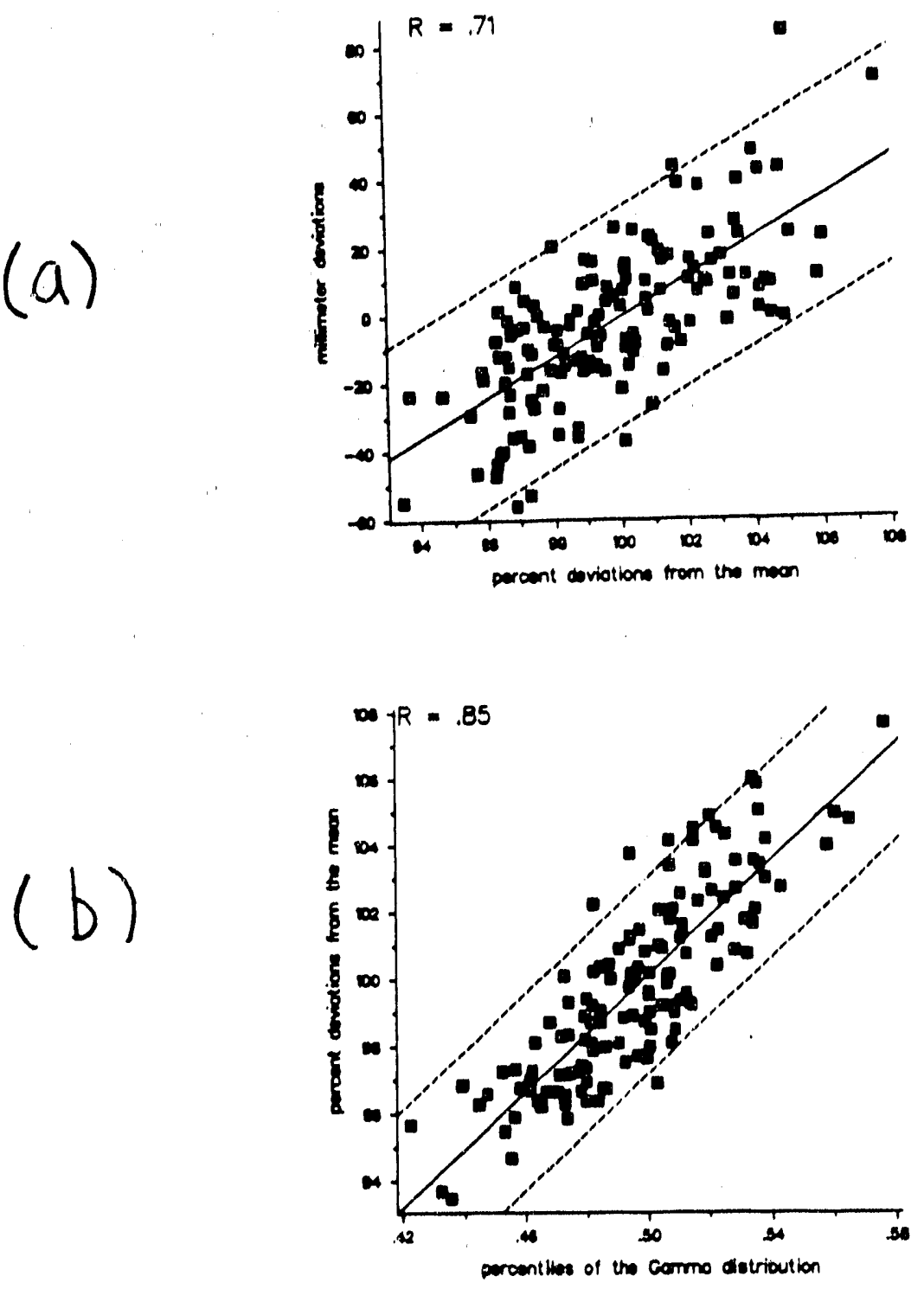

(c)

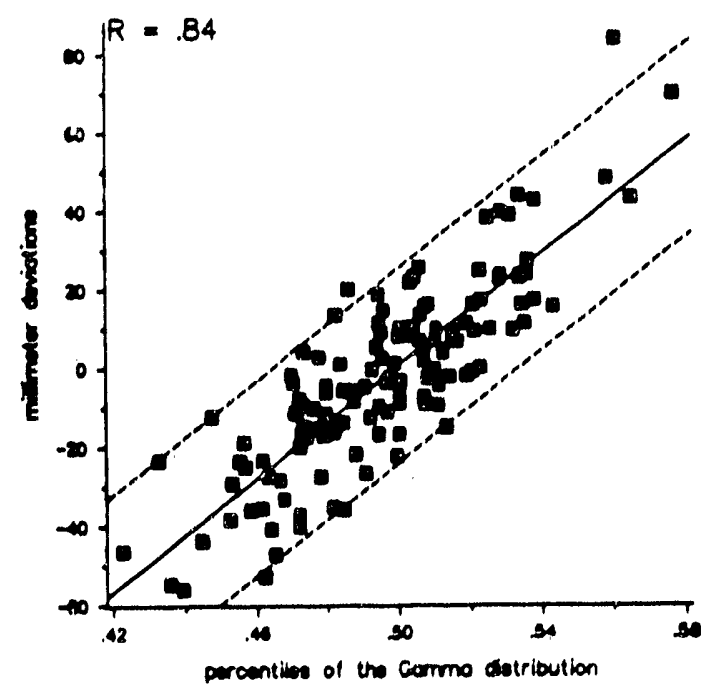

Figure 9. Scatter plots for: (a) millimeter deviations vs. 70 deviations; (b) \%o deviations vs. percentiles: (c) millimeter deviations vs. percentiles. 


\section{APPENDIX $A$}

\begin{tabular}{|c|c|c|c|c|c|}
\hline & lats & & ex Stationr & COUNTRY & by.yri end \\
\hline 10010 & 710 & 84 & OJAN MAYEN & NORWAY & 19221989 \\
\hline 10050 & 780 & -142 & 9ISFJORD RADIO & NORY ' & 19121979 \\
\hline 10250 & 697 & -190 & 9TROMSO/LANGNES & NORH $r$ & 19511989 \\
\hline 10280 & 745 & -190 & 14EJORNOYA & NORWAY & 19511989 \\
\hline 10650 & 695 & -255 & 133KARASJOK & NORWAY & 19011970 \\
\hline 10980 & 704 & -311 & 15VARDO & NORWAY & 19411989 \\
\hline 11520 & 673 & -144 & 138000 & NORWAY & 18691989 \\
\hline 12410 & 637 & -96 & TORLAND & NORWAY & 19511989 \\
\hline 12580 & 634 & -105 & 115 TRONDHEIM/TYHOLT & NORWAY & 19511981 \\
\hline 13160 & 604 & -53 & 44BERGEN/FREDRIKSBERG & NORWAY & 19211989 \\
\hline 13840 & 602 & -111 & 2030SLO/GARDERMOEN & NORWAY & 19511989 \\
\hline 14150 & 589 & -56 & BSTAVANGER/SOLA & NORWAY & 19511989 \\
\hline 14920 & 599 & -107 & $960 S L O / B L I N D E R N$ & NORWAY & 18661989 \\
\hline 20570 & 656 & -221 & 16LULEA FLYGPLATS & SWEDEN & 19511970 \\
\hline 20760 & 599 & -176 & 15UPPSALA & SWEDEN & 17741976 \\
\hline 20800 & 685 & -225 & $327 \mathrm{KARESUANDO}$ & SWEDEN & 18791989 \\
\hline 21270 & 651 & -172 & 327STENSELE & SWEDEN & 18601987 \\
\hline 21530 & 576 & -120 & 31 GOTEBORG & SWEDEN & 18611976 \\
\hline 21960 & 658 & -242 & THAPARANDA & SWEDEN & 18601989 \\
\hline 22260 & 632 & -147 & 2970STEPSUND/FROSON & SWEDEN & 18621989 \\
\hline 23610 & 626 & -180 & BHARNOSAND & SWEDEN & 18601989 \\
\hline 24180 & .594 & -135 & 55KARLSTAD & SWEDEN & 18614989 \\
\hline 24330 & 606 & -156 & 122 FALUN & SWEDEN & 18611976 \\
\hline 24360 & 593 & -152 & $330 R E B O$ & SWEDEN & 18611976 \\
\hline 24460 & 596 & -166 & GVASTERAS & SWEDEN & 18611976 \\
\hline 24530 & 607 & -171 & 32GAVLE & SWEDEN & 18611976 \\
\hline 24640 & 594 & -181 & 52STOCKHOLM/BROMMA & SWEDEN & 18601989 \\
\hline 24991 & 590 & -148 & 175ASKERSUND & SWEDEN & 18611976 \\
\hline 25120 & 577 & -120 & 31GOTEBORG/SAVE & SWEDEN & 19511989 \\
\hline 25219 & 584 & -123 & S4VANERSBORG & SWEDEN & 18611976 \\
\hline 25330 & 584 & -134 & 117 SKARA & SWEDEN & 18611976 \\
\hline 25500 & 578 & -141 & 232 JONKOPINGS AIRPORT & SWEDEN & 18871989 \\
\hline 25620 & 584 & -156 & 64LINKOP ING & SWEDEN & 18611976 \\
\hline 25720 & 588 & -170 & 47NYKOP ING & SWEDEN & 18611976 \\
\hline 25760 & 578 & -166 & 9VASTERVIK & SWEDEN & 18611976 \\
\hline 25900 & 577 & -183 & 28VISBY & SWEDEN & 18611989 \\
\hline 26040 & 567 & -129 & GUHALMSTAD & SWEDEN & 18611976 \\
\hline 26180 & 557 & -132 & 73LUND & SWEDEN & 17481976 \\
\hline 26400 & 569 & -148 & 166VAXJO & SH:EDEN & 18611976 \\
\hline 26491 & 562 & -149 & TKARLSHAMN & SWEDEN & 18611976 \\
\hline 26720 & 567 & -164 & 17KALMAR & SWEDEN & 18611976 \\
\hline 28360 & 674 & -267 & 18OSODANKYLA & FINLAND & 19071989 \\
\hline 28970 & 643 & -277 & 136 KAJAANI & FINLAND & 19511989 \\
\hline 29110 & 631 & -218 & BVAASA & FINLAND & 19511989 \\
\hline 29350 & 624 & -257 & 145JYVASKYLA & FINLAND & 19511989 \\
\hline 29630 & 608 & -235 & 103JOK IOINEN & FINLAND & 19511989 \\
\hline 29720 & 605 & -223 & 54TURKU & FINLAND & 19511989 \\
\hline 29740 & 602 & -2.50 & 58HELS I NK I/SEUTULA & FINLAND & 18451989 \\
\hline 30050 & 601 & 12 & 82 LERWICK & UK & 19311989 \\
\hline 30260 & 582 & 63 & 3STORNOWAY & UK & 19311989 \\
\hline 30291 & 574 & 62 & 2OPORTREE & UK & 18611976 \\
\hline 30380 & 568 & 51 & 66FORT WILLIAM & UK & 18611987 \\
\hline 30381 & 565 & 57 & 69DRIMMIN & UK & 18501976 \\
\hline 30590 & 575 & 42 & 4INVERNESS & UK & 17811972 \\
\hline 30680 & 576 & 31 & 32GORDON CASTLE & UK & 18601972 \\
\hline 30750 & 585 & 31 & 36 WICK & UK & 18501989 \\
\hline 30910 & 572 & 21 & S9ABERDEEN/DYCE & UK & 18291989 \\
\hline 30911 & $56 \%$ & 25 & 57MONTROSE & UK & 18441989 \\
\hline 31000 & 565 & 69 & 9TIREE & UK & 19311989 \\
\hline 31061 & 556 & 62 & 21 EALLABUS & UK & 18001989 \\
\hline 31301 & 549 & 50 & GSTRANRAER & UK & 18171975 \\
\hline 31351 & 556 & 45 & 97KILMARNOCK & UK & 18511976 \\
\hline 31431 & 563 & 45 & 244LOCH KATRINE & UK & 18611976 \\
\hline 31600 & 560 & 34 & 35EDINBURGH AIRPORT & UK & 19511989 \\
\hline 31607 & 559 & 32 & I34EDINB . OBS / /BLACKFORD & DUK & 17851987 \\
\hline 31620 & 553 & 32 & 239 ESKDALEMUIR & UK & 19311989 \\
\hline 31901 & 555 & 20 & B5LILBURN TOWER & UK & 18561987 \\
\hline 32080 & 544 & 44 & 35POINT OF AYRE & UK & 18231976 \\
\hline 32220 & 549 & 30 & 3SCARLISLE CEM/MET $(x)$ & UK & 18451987 \\
\hline
\end{tabular}

Csample first z 


\begin{tabular}{|c|c|c|c|c|c|}
\hline & 543 & 27 & 41KENDAL SCHOOL & UK & 18201987 \\
\hline 151 & 549 & 19 & 116 WHITTLEDEAN RES. & UK & 18501987 \\
\hline 3020 & 533 & 45 & IOVALLEY & UK & 19311989 \\
\hline 3091 & 533 & 37 & 36LLANDUDNO/COLWYN $(x) U$ & )UK & 18591987 \\
\hline 33340 & 534 & 23 & 77MANCHESTER RINGWAY U & UK & 17861989 \\
\hline 33441 & 538 & 16 & 93LEEDS HOLLIES PARK $U$ & UK & 18241987 \\
\hline 3541 & 531 & 11 & 114 WANSF I ELD & UK & 18071987 \\
\hline 33770 & 532 & 5 & 68WADDINGTON & UK & 19511989 \\
\hline 3961 & 537 & 3 & 2HULL PEARSON PARK & UK & 18471987 \\
\hline 34061 & 523 & 36 & 256RHAYADER/TYNANT $(X) l$ & UK & 18581987 \\
\hline 34181 & 527 & 23 & 113SHIFNAL/WESTON PARK L & UK & 18471987 \\
\hline 34621 & 523 & 8 & 122ALTHORP PARK & UK & 18411987 \\
\hline 4951 & 526 & -13 & 2BNORWICH CEMETERY & UK & 986 \\
\hline 4970 & 526 & -17 & 2GORLESTON & UK & 975 \\
\hline 4981 & 528 & 1 & 3PODEHCLE NO. 3 & UK & 987 \\
\hline 5340 & 525 & 17 & 96BIRMINGHAM AIRPORT L & Un' & 989 \\
\hline 6031 & 517 & 51 & 33PEMBROKE/DALE FORT L & UK & 987 \\
\hline 6141 & 515 & 32 & 9CARDIFF BUTE PARK & UK & 987 \\
\hline 37061 & 510 & 42 & 19RIDEFORD/JENNETTS R.L & .UK & 1987 \\
\hline 37750 & 515 & 3 & SKEW GARDENS & UK & 1987 \\
\hline 38270 & 504 & 41 & 27PLYMOUTH/MOUNT BATT,L & UK & 1989 \\
\hline 38271 & 501 & 51 & 51FALMOUTH & UK & 1987 \\
\hline 38390 & 507 & 35 & 32EXETER MET. & UK & 987 \\
\hline 38771 & 509 & 8 & BICHILGROVE HOUSE & UK & 18341987 \\
\hline 38900 & 517 & 12 & 630XFORD & UK & 989 \\
\hline 38951 & 514 & 27 & 91BARROW GURNEY RES. & UK & 18601976 \\
\hline 38991 & 538 & 25 & 115STONYH. /LONGRID. $(X)$ & JUK & 18481987 \\
\hline 38996 & 522 & -1 & 12CAMBRIDGE & UK & 18481987 \\
\hline 38997 & 570 & 34 & MAR & UK & 1973 \\
\hline 39051 & 550 & 76 & ONDERRY & UK & 1976 \\
\hline 39170 & 547 & 62 & AST/ALDERGROVE & UK & 19311989 \\
\hline 39171 & 545 & 60 & AST & UK & 8191976 \\
\hline 39172 & 543 & 66 & $\mathrm{GGH}$ & UK & 18401989 \\
\hline 39538 & 519 & 103 & ENTIA OBSE & YIRELAND & 18611989 \\
\hline 39559 & 519 & 82 & RK AIRPORT & IRELAND & 8361989 \\
\hline 39560 & 523 & 71 & ERFORD & IRELAND & 1971 \\
\hline 39620 & 527 & 89 & TSHANNON AIRPORT & IRELAND & 8611989 \\
\hline 39650 & 531 & 79 & RR & IRELAND & 89 \\
\hline 39680 & 542 & 85 & KREE & IRELAND & 975 \\
\hline 39690 & 534 & 63 & IN AIF & IRELAND & 989 \\
\hline 39700 & 537 & 90 & EMORRIS & IRELAND & 989 \\
\hline 39710 & 535 & 74 & INGAR & IRELAND & 989 \\
\hline 39740 & 542 & 72 & & IRELAND & 1989 \\
\hline 40130 & 651 & 228 & KISHOLMUR & LAND & 1980 \\
\hline 40300 & 641 & 219 & JAVIK & ICELAND & 989 \\
\hline 40480 & 634 & 203 & MANNAEYJAR & ICELAND & 970 \\
\hline 40630 & 657 & 181 & EYRI & ICELAND & 989 \\
\hline 40650 & 666 & 180 & ASEY & ICELAND & 970 \\
\hline 40820 & 643 & 152 & 17HOFN I HORNAFIRDI & ICELAND & 1989 \\
\hline 42020 & 765 & 688 & 11 THULE AFB & GREENLAND & 988 \\
\hline 42100 & 728 & 56 & G3UPERNAVIK & GREENLAND & 981 \\
\hline 42160 & 692 & 51 & 47JAKOBSHAVN & GREENLAND & 970 \\
\hline 42200 & 687 & 52 & EOESMINDE & GREENLAND & 1989 \\
\hline 42500 & 542 & 51 & THAB & GREENLAND & 989 \\
\hline 10 & 612 & 48 & ENNEDAL & GREENLAND & 970 \\
\hline 13200 & 768 & 188 & 11DANMARKSHAVN & GREENLAND & 1889 \\
\hline 43400 & 705 & 220 & $4 I K A P$ TOBIN & GREENLAND & 11889 \\
\hline 43600 & 656 & 376 & 35ANGMAGSSALIK & GREENLAND & 1989 \\
\hline 43900 & 600 & 431 & 76PRINS CHRISTIAN SUND & DOREENLAND & 11989 \\
\hline 60110 & 621 & 68 & 24THORSHAVN & FAROES & 18681989 \\
\hline 60630 & 561 & -93 & DHOLT & DENMARK & 18611971 \\
\hline 61080 & 556 & -85 & RDE & DENMARK & 18611971 \\
\hline 61320 & 557 & -106 & BORNSLUND & DENMARK & 18611976 \\
\hline 61860 & 557 & -126 & 22KOBENHAVN/LANDBOH & SDENMARK & 18211989 \\
\hline 62350 & 530 & -47 & 4DEN HELDER & NETHERLANDS & 18441989 \\
\hline 62600 & 521 & -52 & ODE BILT & NETHERLANDS & 18491989 \\
\hline & 523 & -47 & AHOOFDORP & NETHERLANDS & 17351973 \\
\hline & 532 & -66 & 2GRONINGEN & NETHERLANDS & 18401977 \\
\hline 64470 & 508 & -44 & 104UCCLE & BELGIUM & 18331989 \\
\hline
\end{tabular}



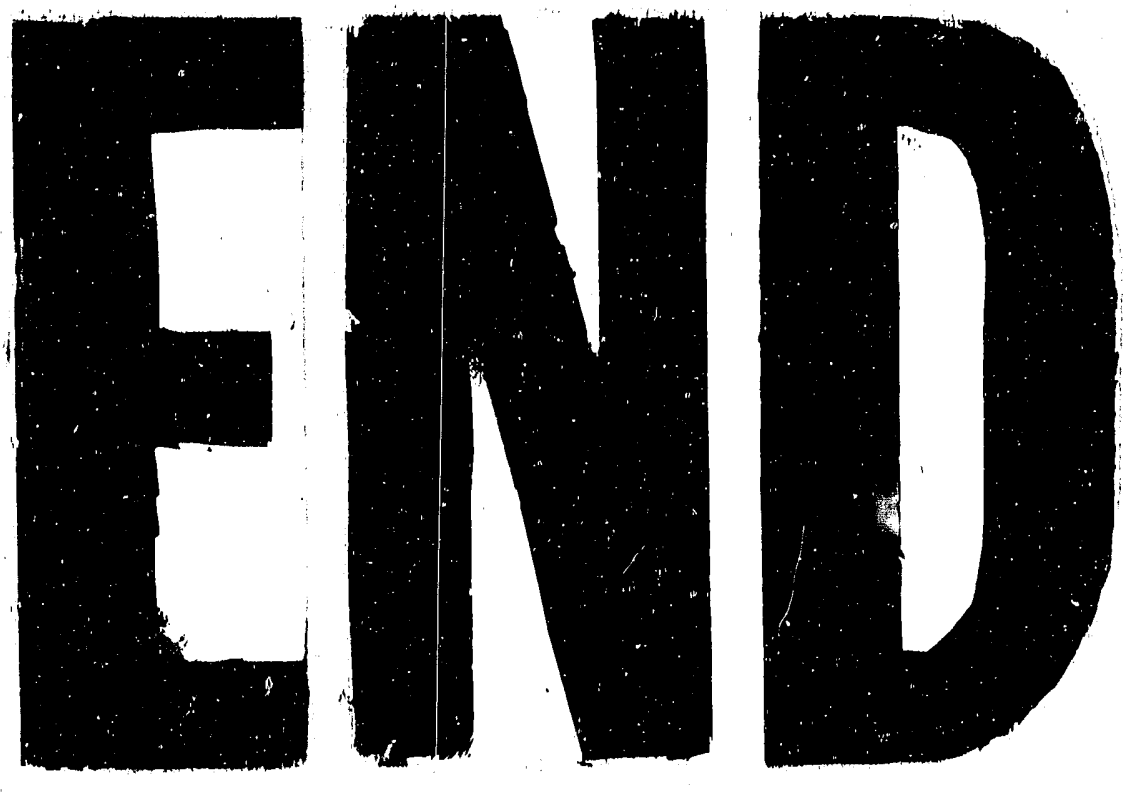

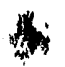
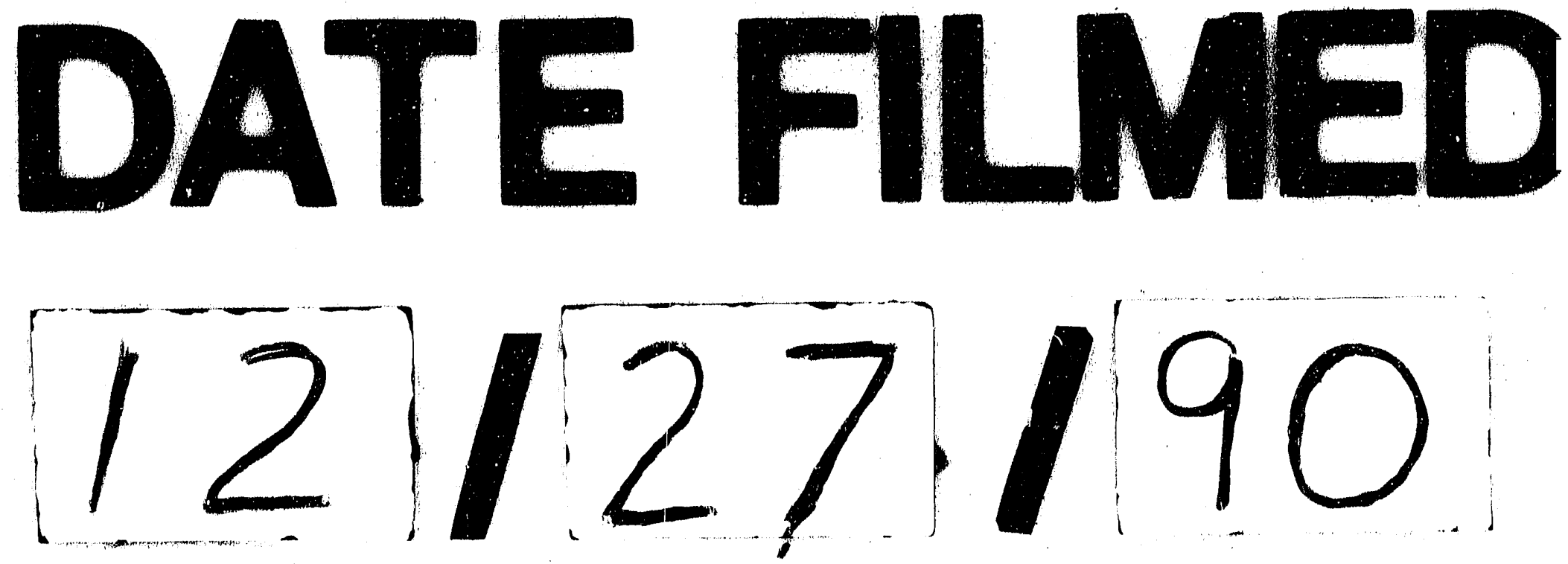
